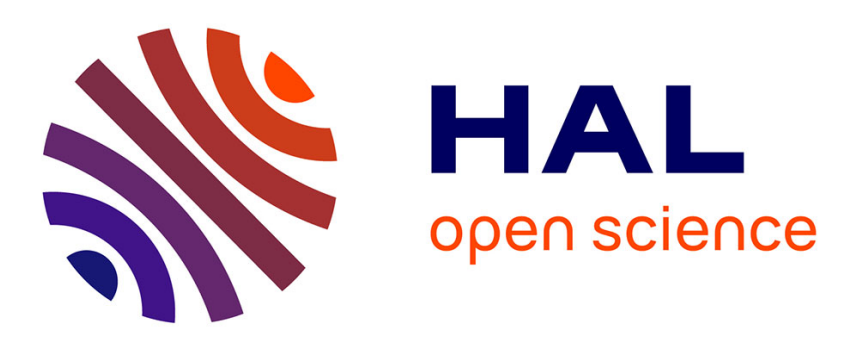

\title{
Trade costs and international strategy of firms: the role of endogenous product differentiation
}

Pierre Blanchard, Carl Gaigné, Claude Mathieu

\section{To cite this version:}

Pierre Blanchard, Carl Gaigné, Claude Mathieu. Trade costs and international strategy of firms: the role of endogenous product differentiation. Regional Science and Urban Economics, 2012, 42 (6), pp.1023-1036. 10.1016/j.regsciurbeco.2012.07.008 . hal-01136961

\section{HAL Id: hal-01136961 https://hal.science/hal-01136961}

Submitted on 30 Mar 2015

HAL is a multi-disciplinary open access archive for the deposit and dissemination of scientific research documents, whether they are published or not. The documents may come from teaching and research institutions in France or abroad, or from public or private research centers.
L'archive ouverte pluridisciplinaire HAL, est destinée au dépôt et à la diffusion de documents scientifiques de niveau recherche, publiés ou non, émanant des établissements d'enseignement et de recherche français ou étrangers, des laboratoires publics ou privés. 


\title{
Trade costs and international strategy of firms: The role of endogenous product differentiation ${ }^{\hbar}$
}

\author{
Pierre Blanchard ${ }^{\text {a }}$, Carl Gaigné ${ }^{\text {b,c,* }}$, Claude Mathieu ${ }^{\text {a }}$ \\ a Université Paris-Est, ERUDITE, UPEC, F-94010, Créteil, France \\ b INRA, UMR1302 SMART, 35000 Rennes, France \\ ' Université Laval, CREATE, Québec, Canada
}

\section{A R T I C L E I N F O}

\section{Article history:}

Received 9 June 2011

Received in revised form 20 July 2012

Accepted 21 July 2012

Available online 11 August 2012

\section{JEL classification:}

F12

F23

L11

L25

Keywords:

Foreign direct investment

Exports

Multi-product competition

Endogenous differentiation product

Trade integration

\begin{abstract}
A B S T R A C T
We study the impact of trade liberalization on the international strategy of firms (to export and/or invest abroad as well as the number of varieties to be produced) when product differentiation is endogenous. By considering product differentiation as a strategic variable, our analysis sheds new light on the impact of trade barriers on the decision to produce abroad and on the choice of product range, in accordance with recent empirical evidence. We show, even though technology exhibits the same productivity for each variety, firms drop some of varieties with trade integration. In addition, our results reveal that, contrary to the standard theoretical literature, the relationship between the decision to export and trade costs is non-linear. When trade costs are relatively high, firms may export and be multi-product. Finally, the choice of producing abroad results from either a prisoner's dilemma game or a chicken game.
\end{abstract}

(c) 2012 Elsevier B.V. All rights reserved.

\section{Introduction}

The predominance of large multi-product firms in international trade is well documented (Bernard et al., 2009). For example, in the United States in the year 2000, the top 1\% of trading firms accounted for over $80 \%$ of total trade value, while the share of exports attributable to firms that export a single product was only $0.4 \%$. Recent empirical studies have focused on the product-range decision at the firm level in response to trade liberalization. This literature suggests that trade liberalization has induced firms located in various countries (e.g., Canada, France, Mexico, U.S.A.) to reduce the number of varieties they produce (see Baldwin and Gu, 2009; Bernard et al., 2011; Berthou and Fontagné, forthcoming;

\footnotetext{
is The authors thank the two anonymous referees for their very helpful comments and very detailed reports. Carl Gaigné also thanks Jacques Thisse, a wonderful colleague and a friend, for his useful comments on the first draft of this paper. This paper was produced in the framework of MICRO-DYN (www.micro-dyn.eu), an international research project funded by the EU Sixth Framework Programme (www. cordis.lu) with socio-economic sciences and humanities (http://ec.europa.eu/research/ social-sciences/index_en.html). This publication reflects only the author's views, the European Community is not liable for any use that may be made of the information contained therein.

* Corresponding author at: INRA, UMR1302 SMART, 35000 Rennes, France.

E-mail address: carl.gaigne@rennes.inra.fr (C. Gaigné).
}

Iacovone and Javorcik, 2010; Mayer et al., 2011). In other words, trade openness may lead to an anti-variety effect or, equivalently, to a reduction in the range of products at the firm level. The main explanation, according to this literature, lies in the fact that liberalization causes a rationalization of production in response to tougher product competition because firms drop their less profitable products and concentrate on their most successful varieties. However, in its assessment of the impact of falling trade barriers on firms' product selection, the literature has generally failed to consider two characteristics of the firms that dominate international trade. First, the literature on firms' export strategy does not consider that product differentiation may be a strategic variable for large firms. This omission is a problem because we know from the industrial organization literature that the introduction or removal of a new variety and the degree of differentiation within a product-range are two strategic decisions that are strongly related to each other within large firms (see Manez and Waterson, 1998, for a review). Each firm has an incentive to produce additional varieties to increase its operating profits (i.e., through a market-expansion effect). However, by introducing new varieties, the firm's profit may decrease because of fiercer price competition between the varieties that it supplies to the market (i.e., through a cannibalization effect) (see Anderson et al., 1992 [chapter 7]; Brander and Eaton, 1984; Shaked and Sutton, 1990). Clearly, large firms are able to manage both effects to reduce price competition by adjusting 
the degree of product differentiation between their own varieties and the varieties supplied by their rivals.

Additionally, large firms can also react to trade liberalization by shifting the production of some varieties abroad. Indeed, trade liberalization has also been accompanied by an increase in the flows of foreign direct investment (FDI), especially in major industrialized countries (UNCTAD, 2006). During the period from 2000 to 2005, the average annual FDI outflows from developed countries accounted for $67 \%$ of world FDI inflows, whereas the average annual FDI inflows in developed countries reached $74 \%$ of world FDI outflows. The fact that these inward and outward FDI flows (i.e., cross-hauling FDI flows) occur within the same industry is well documented (Rugman, 1987; Greenaway et al., 1998). For example, American automakers such as Ford produce in Europe, and reciprocally, European automakers such as Volkswagen own subsidiaries in the North America Free Trade Area. In this context, multinational firms (MNFs) can supply a large product range abroad to prevent their foreign rivals from developing their own product range. As noted by Markusen (2002), multinational corporations are characterized by high levels of product differentiation and advertising. Hence, choices regarding the degree of product differentiation and the geographical location of production are both strategic choices that are made to handle spatial competition between rival firms (Ben-Akiva et al., 1989).

This paper addresses both dimensions of firms' strategic decisions. More precisely, our objective is to provide a unified framework that can be used to study the effect of trade integration on the international strategies of multi-product firms when they make strategic decisions regarding the degree of product differentiation of their varieties and whether to produce abroad. To achieve this goal, we adopt a game theory approach and develop a two-country model of Hotelling-type competition. In our framework, the firms adjust the characteristics of their products by taking into account the two following (traditional) trade-offs: (i) firms can serve a foreign country either by producing in the foreign country to save trade costs (the tariff jumping argument) or by exporting to avoid the additional fixed costs related to setting up a new affiliate (the "proximity-concentration" trade-off); and (ii) firms can either introduce a new variety to increase sales (the market expansion effect) or drop a variety to reduce competition among varieties produced by the same supplier (cannibalization effect). To this end, we analyze the role of endogenous product differentiation on the relationship between falling trade barriers and the international strategies of firms.

Our analysis contributes to two streams of literature. First, the recent literature on export strategies assumes that firms are multiproduct firms and are heterogeneous in productivity (Baldwin and Gu, 2009; Bernard et al., 2009; Mayer et al., 2011). However, this literature does not consider endogenous product differentiation and the cannibalization effect. A few studies (Feenstra and Ma, 2008; Eckel and Neary, 2010) have developed models of multi-product heterogeneous firms incorporating the cannibalization effect, but they all restrict their analysis to a single globalized world with no trade costs and consider only exogenous product differentiation. Our model captures the relationships among trade barriers, endogenous product differentiation, and the cannibalization effect.

Second, the role of endogenous product differentiation in the emergence of FDIs has also received little formal attention. In most theoretical works on MNFs, product differentiation is exogenous and/or firms produce a single product (see Markusen, 2002; Navaretti and Venables, 2004). Lyons (1984) first proposed a framework incorporating endogenous product differentiation based on Hotelling (1929), but he considers that MNFs pursue cooperative pricing and differentiation to prevent entry of potential competitors. ${ }^{1}$ The studies by Motta

\footnotetext{
1 Lyons (1984) examines whether a first mover can establish a monopoly outcome in its domestic market by implementing a strategy of variety proliferation under sequential entry. He shows that widening the product range by an MNF (or by several cooperating MNFs) in different countries raises barriers to entry.
}

(1994), Mathieu (1997) and DeFraja and Norman (2004) are also among the exceptions. Motta (1994) focuses on the role of vertical differentiation and trade costs in international trade and investments. However, each firm's decision regarding internationalization is subject to the constraint that the firm's product quality is exogenous. Mathieu (1997) and DeFraja and Norman (2004) analyze how product differentiation influences a firm's choice between exporting and producing abroad when consumers have heterogeneous tastes across varieties. However, our analysis is more general because we allow for the possibility that firms may produce more than one variety. The study by Baldwin and Ottaviano (2001) is noteworthy because it recognizes that multinationals are multiproduct firms, although the degree of product differentiation is assumed to be exogenous and the only way multinational firms handle the cannibalization effect is assumed to be through the production of varieties abroad.

Three main conclusions concerning the effect of trade liberalization on the international strategy of large firms can be drawn from our theoretical analysis. First, exports occur even when trade costs are relatively high. This equilibrium results from the ability of firms to be multi-product firms. High tariff barriers introduce asymmetric competition in favor of firms in their own domestic markets. High trade costs relax price competition and favor the market-expansion effect at the expense of the cannibalization effect. As a result, each firm prefers to be a multi-product exporter rather than to be a multinational to avoid strong price competition. This result is consistent with the weak empirical relationship found in some studies between trade costs and the probability of producing abroad (Brainard, 1997; Ekholm, 1997). $^{2}$

Second, the decision to produce abroad depends on the level of sunk costs involved in setting up a plant abroad. When this additional cost is sufficiently low, the firms are multinationals. Each company has an incentive to set up a second plant abroad rather than to export. Consequently, price competition becomes so fierce that each firm reduces its product range by eliminating one of its products and choosing the maximum differentiation vis-à-vis its rival. In this case, the cannibalization effect predominates over the market expansion effect. This result is consistent with the empirical evidence showing that FDI is cross-hauling between countries. In addition, this two-way FDI Nash equilibrium results from a prisoner's dilemma game in which the FDI strategy predominates over the export strategy for each firm, even though export strategies lead to a Pareto optimal outcome. Hence, firms may end up being trapped in a prisoner's dilemma, provided that the sunk cost of setting up a plant abroad is low enough. Moreover, when trade costs are sufficiently high, oneway FDI and exports are modeled as a chicken game. In this case, there exist two Pareto optimal Nash equilibria in which one firm becomes multinational while its rival produces at home and exports abroad. It is important to stress that such an asymmetric outcome can occur in a perfectly symmetric environment. In other words, a multinational multi-product corporation and a national singleproduct firm may coexist, even though the firms share the same technologies and the countries have the same size.

Third, we show that trade liberalization and the emergence of multinationals lead to a decline in the available range of product varieties, in contrast to the well-known Krugman variety effect. In other words, more competition may lead to less product variety. Norman and Thisse (1996) obtain similar results with single-product firms without international trade. In our case, we show that for a given number of firms, each rival reduces the number of varieties it supplies when trade costs shrink. As shown in Bernard et al. (2011),

\footnotetext{
2 These results are obtained from a probit model of FDI decisions. However, empirical studies on the level of foreign activities show that trade costs have a significant positive effect on the level of affiliate production (see Navaretti and Venables, 2004; Neary, 2009).
} 
trade liberalization leads to a rationalization of production in which firms drop their low-productivity products. In our study, firms respond to trade integration by rationalizing their product range by dropping some varieties due to a cannibalization effect and to the fact that FDI can occur in our model.

This paper is organized as follows. We describe the model in Section 2. In Section 3, we focus on equilibrium prices and the supply of varieties. More specifically, we analyze how trade integration can affect prices, product differentiation and product range when the location of plants is fixed. In Section 4, we determine the conditions under which firms decide strategically either to become multinationals or to serve the foreign market via exports. Finally, in Section 5 , we offer some concluding remarks.

\section{A two-country model of multi-product competition with endogenous product differentiation}

\subsection{The basic structure}

Consider an economy with two countries $(r=H, F)$ and two rival firms $(f=A, B)$. We consider one firm per country: the headquarter of firm $A$ (resp., $B$ ) is always located in country $H$ (resp., $F$ ). Each firm may be multi-product but, for the sake of convenience, it can produce at most two products or varieties. ${ }^{3}$ To ensure that our results would be comparable to the results obtained in the literature on international trade, we assume there is no intra-firm trade when a horizontal multinational firm emerges. This assumption is discussed in Section 4. In addition, the firms practice third-degree price discrimination without the threat of arbitrage by consumers.

We assume a horizontal product differentiation in which each variety $i$ can be described by a set of technical characteristics, $x_{i}$, which are positioned along a line in the tradition of Hotelling (1929) with $x_{i} \in[0,1]$. Note that $x_{i}$ is not specific to a country. Because four varieties can be produced at most, we have $i=1,2,3,4$ (i.e., at most four varieties are available in the economy). Moreover, we assume, without loss of generality, that $0 \leq x_{1} \leq x_{2} \leq x_{3} \leq x_{4} \leq 1$.

Each rival firm has either one plant (located at home) or two plants (one located at home and the other located abroad). Hence, the firms serve the foreign country either by exporting or by producing abroad. If the firms export, each unit of a variety is carried between the two countries at a (positive) specific cost $t$. This trade cost is borne by firms and includes transport, tariffs, customs, bureaucracy and any other costs arising from the socio-legal constraints associated with selling in a foreign environment. If a firm produces abroad, it must pay a fixed sunk cost $\Gamma$. This fixed cost $\Gamma$ is a positive plant-specific cost in connection with the creation of a foreign subsidiary. This cost can come from the transfer of firm-specific assets abroad and from entry into the foreign market.

\subsection{Technology}

Firms share the same technology. This assumption implies the following cost function: $c q_{\mathrm{f}}+\Phi$ where $\Phi$ is a fixed sunk cost, $q_{\mathrm{f}}$ is the total output of each firm $f$ and $c$ is the unit cost, which is normalized at $0(c=0)$ without loss of generality. Using a horizontal product differentiation approach, we can assume that there are no costs of product differentiation. Thus, there is no additional cost due to the introduction of a new variety, and the cost of production of any particular variety is the same for each firm, regardless of the number of varieties that it may produce. When a firm exports from its home country, we have $\Phi=\Phi_{N}$, whereas $\Phi=\Phi_{N}+\Gamma$ applies when the firm

\footnotetext{
${ }^{3}$ Note there is no clear evidence that firms offer different varieties at home and abroad. Indeed, some empirical studies suggest that firms choose the same variety to serve both domestic and foreign markets (Ojah and Monplaisir, 2003; Iacovone and Javorcik, 2010)
}

is multinational and produces in both countries. Following Horstman and Markusen (1992), whereas $\Gamma$ is assumed to be a plant specific cost, $\Phi_{N}$ must be viewed as a firm-specific cost, i.e., a cost resulting from specific assets developed by the firms and, to a wider extent, based on the firms' R\&D.

\subsection{Demand}

Consumers are assumed to have different tastes, which can be represented by a position along the same line as that describing the technology. Thus, in each country $r=H, F$, the consumers are located, according to their preferences, on the interval $[0,1]$ with a uniform density $\Delta_{r}$. We assume that this density is the same for both markets $\left(\Delta_{H}=\Delta_{F}=1\right)$, which are thus the same size. When consumer $j$ living in country $r$ consumes one unit of variety $i$, her/his preferences are represented by the following indirect utility function:

$V_{r j}=R-\left(x_{i}-x_{j}\right)^{2}-p_{r i}$

where $R$ is the individual income, which is the same for all consumers in the two countries, $x_{j} \in[0,1]$ is the technical characteristic of the ideal good of this consumer, $x_{i}$ is the technical characteristic of variety $i$, and $p_{r i}$ is the selling price of this variety in country $r$. The term $\left(x_{i}-x_{j}\right)^{2}$ measures the disutility incurred by consumer $j$ when she/he consumes a variety other than her/his ideal product (see D'Aspremont et al., 1979). ${ }^{4}$ Product $i$ is effectively purchased by this consumer whenever this purchase leads to a maximum level of indirect utility with respect to other products that are available and as long as the value of the utility function is positive. We assume that each consumer always buys one unit of a variety and that both markets are fully covered. We assume that $x_{j}$ is not specific to a country, but the price of a variety $\left(p_{r i}\right)$ varies depending on the country in which the consumer lives (third-degree price discrimination). Therefore, the indirect utility is specific to a consumer and to a country.

A consumer chooses good $i$ if the choice causes her/his utility to be higher than what s/he would experience by consuming another product such as $i+1$ or $i-1$. As a result, all consumers located in the interval $\left[0, x_{r 12}\right]\left(\left[x_{r 12}, x_{r 23}\right],\left[x_{r 23}, x_{r 34}\right]\right.$, and $\left.\left[x_{r 34}, 1\right]\right)$ will address their demand to the producer of variety 1 (2, 3 and 4 , respectively), where $x_{r, i, i+1}$ corresponds to the set of technical characteristics that is most preferred by the consumers who are indifferent between purchasing good $i$ or $i+1$ given prices $p_{r i}$ and $p_{r i+1}$ and technical characteristic $x_{i}$ and $x_{i+1}$. Thus, from Eq. (1), we obtain:

$x_{r i, i+1}=\frac{p_{r i+1}-p_{r i}}{2\left(x_{i+1}-x_{i}\right)}+\frac{x_{i+1}+x_{i}}{2}$

for each country. Therefore, the demand for each variety $i=1,2,3,4$ prevailing in country $r$ is expressed as follows:

$$
\begin{aligned}
& q_{r 1}=x_{r 12}-0=\frac{p_{r 2}-p_{r 1}}{2\left(x_{2}-x_{1}\right)}+\frac{x_{2}+x_{1}}{2}, \\
& q_{r 2}=x_{r 23}-x_{r 12}=\frac{p_{r 3}-p_{r 2}}{2\left(x_{3}-x_{2}\right)}-\frac{p_{r 2}-p_{r 1}}{2\left(x_{2}-x_{1}\right)}+\frac{x_{3}-x_{1}}{2}, \\
& q_{r 3}=x_{r 34}-x_{r 23}=\frac{p_{r 4}-p_{r 3}}{2\left(x_{4}-x_{3}\right)}-\frac{p_{r 3}-p_{r 2}}{2\left(x_{3}-x_{2}\right)}+\frac{x_{4}-x_{2}}{2}, \\
& q_{r 4}=1-x_{r 34}=1-\frac{p_{r 4}-p_{r 3}}{2\left(x_{4}-x_{3}\right)}-\frac{x_{3}+x_{4}}{2} .
\end{aligned}
$$

\footnotetext{
${ }^{4}$ Following Ben-Akiva et al. (1989), we consider linear transportation costs in geographic space and quadratic costs of deviation from the most preferred product in brand space.
} 


\subsection{Type of product competition}

Without loss of generality, we assume that firm $A$ always produces variety 1 . Nevertheless, this firm can also choose to produce a second variety among varieties 2,3 or 4 . Hence, two types of product competition may arise: (i) the case of "market segmentation" in which firm $A$ also produces variety 2 and varieties 3 and 4 belong to firm $B$; (ii) the case of "market interlacing" in which firm $A$ produces varieties 1 and 3 whereas varieties 2 and 4 are supplied by firm $B$. In this case, the best substitutes are supplied by both rivals. Ideally, it should be possible by using a game theory approach to determine the choice of varieties produced by each firm or, equivalently, to choose between the two types of competition (see Martinez-Giralt and Neven, 1988 and Klemperer, 1992). However, throughout this paper, we assume that "market segmentation" prevails as long as trade occurs. ${ }^{5}$ Hence, firms are single-product when $x_{1}=x_{2}$ and $x_{3}=x_{4}$ while they are multi-product when $x_{1}<x_{2}$ and $x_{3}<x_{4}$.

\subsection{Types of trade}

Three types of international relationships can emerge. First, in NN configuration, both firms are $\mathrm{N}$-type, that is, each firm exports from its home country to serve the foreign market. In this case, intraindustry trade occurs but no FDI takes place. Second, in MM configuration, both firms are M-type, that is, each sets up a second plant abroad. Hence, cross-hauling FDI in the same industry prevails. Third, in NM configuration, one firm is N-type, whereas its rival is Mtype. Under this asymmetric configuration, one country exports and has inward FDI, whereas the other country imports and has outward FDI.

In accordance with the objectives of this paper, we do not consider the possible cases in which there is a monopoly equilibrium in both markets. In other words, even though trade and foreign location are not completely free in our model, we assume that the trade and location barriers are not sufficiently high to achieve an autarky equilibrium.

\subsection{Sequence of events}

Following DeFraja and Norman (2004) and Mathieu (1997), we represent competition between firms by a three-stage game: 1 . the choice between exports and foreign direct investment, 2. product specification, and 3. price competition. The decisions are made simultaneously by the two firms in each stage depending on the choices made in the previous stages. The solution concept is a subgame perfect Nash equilibrium. In stage one, each firm decides either to produce its varieties at home (N-type) or to be multinational (M-type). ${ }^{6}$ In the second stage, each rival chooses the technical characteristic of its varieties. In this way, each firm determines the number of varieties that it will supply and their degree of differentiation. These two elements characterize the product range of both firms. In the last stage, the prices of each variety are set in a Bertrand competition sub-game. The order of the three stages can be justified by the facts that prices are more flexible than product specifications and plant location is less flexible than product specification. This sequential game is solved, as usual, by backward induction to obtain the perfect Nash equilibrium in pure strategies.

\footnotetext{
5 One could also consider a "surrounded competition" configuration in which firm $A$ produces varieties 1 and 4 . In this case, the worst substitutes are produced by firm $A$. However, in this case, the firms are not symmetrical. In addition, the surrounded competition is equivalent to a configuration in which two single-product firms compete with a multi-product firm.

${ }^{6}$ The configuration in which each firm produces all of its own varieties in the foreign country is never an outcome because that configuration would cause the firm to incur trade costs as well as plant-specific costs $(\Gamma)$.
}

\section{Equilibrium price and product range with international trade (stages 2 and 3)}

In this section, we analyze the optimal price and product strategies of each firm. These strategies correspond to stages two and three of our game as described in Section 2. Each firm can practice third-degree price discrimination (markets are segmented), and each firm faces positive trade costs that reduce international competition and lead to partial trade integration. Equilibrium prices and product characteristics must be determined for each of the three following configurations that may arise in stage one of the game: (i) both firms export from their home country (NN-type); (ii) both firms are multinational (MM-type); and (iii) only one firm is multinational while the other exports (MNtype). Note that the first two configurations are symmetric while the third configuration is asymmetric. The equilibrium profits are also calculated in each case because the comparison of profits allows us to determine the perfect Nash equilibrium in stage one of the game. In the next section, we will see that each of these three configurations can be a perfect Nash equilibrium.

\subsection{Firms produce exclusively in their domestic country (NN-type)}

For each firm, varieties are produced and sold at home and exported abroad. Therefore, in this configuration, no FDI takes place. Tariff protection distorts competition, and two opposite mechanisms are at work. First, trade barriers give an advantage to each firm in its home market. Second, these barriers reduce every firm's access to the foreign market. The first mechanism reduces inter-firm competition in the domestic market and it may be profitable for each firm to introduce a second variety (i.e., a market expansion effect appears in this case). Conversely, the second mechanism favors maximum differentiation between the varieties produced by rivals as exporters attempt to limit the decline of their market share abroad. In what follows, we show that the first mechanism prevails over the second when trade barriers are sufficiently high.

The profit functions for firms A and B, respectively, are given by:

$$
\begin{aligned}
\pi_{\mathrm{A}}^{\mathrm{NN}}= & p_{\mathrm{H} 1} q_{\mathrm{H} 1}+\max \left[\left(p_{\mathrm{F} 1}-t\right), 0\right] q_{\mathrm{F} 1}+p_{\mathrm{H} 2} q_{\mathrm{H} 2} \\
& +\max \left[\left(p_{\mathrm{F} 2}-t\right), 0\right] q_{\mathrm{F} 2}-\Phi_{N} \\
\pi_{B}^{\mathrm{NN}}= & p_{\mathrm{F} 3} q_{\mathrm{F} 3}+\max \left[\left(p_{\mathrm{H} 3}-t\right), 0\right] q_{\mathrm{H} 3}+p_{\mathrm{F} 4} q_{\mathrm{F} 4} \\
& +\max \left[\left(p_{\mathrm{H} 4}-t\right), 0\right] q_{\mathrm{H} 4}-\Phi_{\mathrm{N}}
\end{aligned}
$$

We restrict our analysis to the regime under which both firms export at least one variety which is equivalent to consider the case where $p_{\mathrm{F} 2} \geq t$ and $p_{\mathrm{H} 3} \geq t$ (because $p_{\mathrm{F} 1}>p_{\mathrm{F} 2}$ and $p_{\mathrm{H} 4}>p_{\mathrm{H} 3}$ as we will see below). We disregard the regime under which both firms export at most one variety even if they produce two varieties because this introduces additional cases while the gains in terms of results are very limited. ${ }^{7}$ This point is discussed in the end of this subsection.

The profit maximizing prices for firms $A$ and $B$ are reported in Appendix A.1. As expected, the equilibrium prices for each variety increase with trade costs and with distance to close substitutes $\left(x_{3}-x_{2}\right)$. Hence, product differentiation and trade costs relax price competition. However, each firm has to manage both cannibalization effect and interfirm competition. More precisely, ceteris paribus, reducing inter-firm competition by increasing $x_{3}-x_{2}$ leads to an increase in intra-firm product cannibalization (prices of varieties 1 and 4 decreases).

Note also exports are profitable if and only if $p_{\mathrm{F} 2}-t>0$ and $p_{\mathrm{H} 3}-t>0$ (because $p_{\mathrm{F} 2} \leq p_{\mathrm{F} 1}$ and $p_{\mathrm{H} 3} \leq p_{\mathrm{H} 4}$ ) or, equivalently,

$t<t_{2}^{\max } \equiv\left(x_{3}+x_{2}+2\right)\left(x_{3}-x_{2}\right) \in[0,3]$

\footnotetext{
${ }^{7}$ Under this regime, the profits of firm A are given by $\pi_{A}^{\mathrm{NN}}(t)=p_{\mathrm{H} 1} q_{\mathrm{H} 1}+\max \left\{\left(p_{\mathrm{F} 1}-t\right), 0\right\}$ $q_{\mathrm{F} 1}+p_{\mathrm{H} 2} q_{\mathrm{H} 2}-\Phi_{\mathrm{N}}$.
} 
$t<t_{3}^{\max } \equiv\left(4-x_{3}-x_{2}\right)\left(x_{3}-x_{2}\right) \in[0,3]$.

Using equilibrium prices (given in Appendix A.1), firm A's profit differentiation with respect to $x_{1}$ is given by:

$\frac{\mathrm{d} \pi_{\mathrm{A}}^{\mathrm{NN}}}{\mathrm{d} x_{1}}=-\frac{\left(x_{1}+x_{2}\right)\left(3 x_{1}-x_{2}\right)}{4}$

with $\mathrm{d}^{2} \pi_{\mathrm{A}} / \mathrm{d} x_{1}^{2} \leq 0$ regardless of $x_{1}$ and $x_{2}$. Two opposite effects are at work. On the one side, increasing $x_{1}$ lowers the price of variety 1 prevailing in both countries due to the cannibalization effect between the varieties supplied by firm $A$. On the other side, rising $x_{1}$ yields a higher market share for variety 1 at the expense of variety 2 in both countries. It appears that the optimal technical characteristic for variety 1 is given by $x_{1}^{*}=x_{2} / 3$ regardless of $t, x_{3}$, and $x_{4}$. Note that $x_{1}^{*}$ does not depend directly on trade costs and on the characteristics of the varieties produced by firm $B$. Indeed, the characteristics of variety 1 do not directly influence the total market share of firm $A\left(q_{r 1}+q_{r 2}\right.$ does not depend directly on $x_{1}$ ). We obtain similar results for variety 4 produced by firm $B$. Indeed, maximizing the profit function with respect to $x_{4}$ leads to

$\frac{\mathrm{d} \pi_{\mathrm{B}}^{\mathrm{NN}}}{\mathrm{d} x_{4}}=\frac{\left(2-x_{3}-x_{4}\right)\left(-3 x_{4}+x_{3}+2\right)}{4}$

with $\mathrm{d}^{2} \pi_{\mathrm{B}} / \mathrm{d} x_{4}^{2} \leq 0$, regardless of $x_{3}$ and $x_{4}$. Thus, the optimal technical characteristic for variety 4 is $x_{4}^{*}=\left(2+x_{3}\right) / 3$ regardless of $t, x_{2}$, and $x_{3}$.

Because, $x_{1}^{*}=x_{2} / 3$, the profit differentiation with respect to $x_{2}$ becomes:

$\left.\frac{\mathrm{d} \pi_{\mathrm{A}}^{\mathrm{NN}}}{\mathrm{d} x_{2}}\right|_{x_{1}=x_{1}^{*}}=\frac{t^{2}}{9\left(x_{3}-x_{2}\right)^{2}}-\frac{\left[4\left(1+2 x_{2}-x_{2}^{2}\right)-\left(x_{3}-x_{2}\right)^{2}\right]}{9}$.

The different mechanisms at work are as follows. By increasing $x_{2}$ (i.e., by having a higher product differentiation across the varieties supplied by firm $A$ and a lower product differentiation across the varieties produced by the rivals), firm $A$ raises its total market share in both countries $\left(q_{r 1}+q_{r 2}\right)$ for any given price but reduces the price of its variety (see Appendix A.1). In addition, by changing $x_{2}$, firm A modifies also the prices and the market share of variety $1\left(q_{r 1}\right)$. More precisely, because $p_{\mathrm{H} 1}-p_{\mathrm{H} 2}=p_{\mathrm{F} 1}-p_{\mathrm{F} 2}=\left(x_{1}^{2}-x_{2}^{2}\right) / 2=8 x_{2}^{2} / 18 \geq 0$, firm $A$ increases the market share of the variety with the higher price (variety 1 ) by increasing $x_{2}$. It also appears that the incentives to introduce a new product $\left(x_{2}>x_{1}\right)$ and to increase $x_{2}$ are higher when trade costs reach higher values. In this case, inter-firm competition is relaxed. However, when $t=0, \mathrm{~d} \pi_{A} / d x_{2}<0$ when $x_{1}=x_{1}^{*}$ regardless of $x_{3}$ because $4\left(1+2 x_{2}-x_{2}^{2}\right)-\left(x_{3}-x_{2}\right)^{2}>0$.

Similar mechanisms are at work for firm B. Indeed, using $x_{4}^{*}=\left(2+x_{3}\right) / 3$, we have

$\left.\frac{\mathrm{d} \pi_{\mathrm{B}}^{\mathrm{NN}}}{\mathrm{d} x_{3}}\right|_{x_{4}=x_{4}^{*}}=\frac{-t^{2}}{9\left(x_{3}-x_{2}\right)^{2}}+\frac{4\left(2-x_{3}^{2}\right)-\left(x_{3}-x_{2}\right)^{2}}{9}$.

Two sub-cases must be distinguished according to the level of trade costs to determine the equilibrium technical characteristics of varieties 2 and 3. The details of results are reported in Appendix B.

a. First, the outcome $x_{1}^{*}=x_{2}^{*}=0$ and $x_{3}^{*}=x_{4}^{*}=1$ is an equilibrium if and only if $t<\bar{t} \equiv \sqrt{3}$ where $\bar{t}<t_{i}^{\max }$ with $i=2,3$ (see Appendix B). In Appendix $B$, we show that there exists also an interior equilibrium if and only if $\sqrt{3}>t>1.66$ with $0<x_{2}^{*}<0.07$ and $x_{3}^{*}=1-x_{2}^{*}$. However, as in Baldwin and Ottaviano (2001), we use the Pareto refinement when there are multiple equilibria. We consider that if a particular equilibrium is Pareto dominated by another, firms would be able to coordinate to avoid the inferior outcome. In Appendix B, we show that the profits reach highest values when firms produce a single variety. As a result, we consider only the case where $x_{1}^{*}=x_{2}^{*}=0$ and $x_{3}^{*}=x_{4}^{*}=1$ when $t \leq \bar{t}$.

Hence, low trade costs (including the case of free trade) imply maximum product differentiation between varieties produced by the rivals. Consequently, each firm becomes a single-product firm when trade costs are low enough. In other words, when trade costs reach low values, the minimum differentiation between varieties 1 and 2 holds, even though the variety produced by the foreign rival is imported with positive trade costs. Under these circumstances, the cannibalization effect is stronger than the market expansion effect. Therefore, each firm manages inter-firm competition by restricting its product range to avoid fierce international competition.

Hence, equilibrium prices of varieties 1 and 2 are as follows:

$p_{\mathrm{H} 1}^{*}=p_{\mathrm{H} 2}^{*}=1+t / 3$ and $p_{\mathrm{F} 1}^{*}=p_{\mathrm{F} 2}^{*}=1+2 t / 3$

and, by symmetry, the equilibrium prices of varieties 3 and 4 are given by $p_{\mathrm{F} 3}^{*}=p_{\mathrm{F} 4}^{*}=p_{\mathrm{H} 2}^{*}$ and $p_{\mathrm{H} 3}^{*}=p_{\mathrm{H} 4}^{*}=p_{\mathrm{F} 2}^{*}$, respectively. As a result, the domestic demand for each firm's variety is given by $q_{\mathrm{H}}^{\mathrm{A}}=q_{\mathrm{F}}^{\mathrm{B}}=(1+t / 3) / 2>1 / 2$ while the foreign demand is $q_{\mathrm{F}}^{\mathrm{A}}=q_{\mathrm{H}}^{\mathrm{B}}=1-q_{\mathrm{H}}^{\mathrm{A}}<1 / 2$ when $t<\bar{t}$. Trade costs imply that the price at home is lower than the price abroad and, correlatively, that domestic sales are higher than foreign sales. Finally, the profits of each firm are equal and are given by $\pi_{\mathrm{A}}^{\mathrm{NN}}(t<\bar{t})=\pi_{\mathrm{B}}^{\mathrm{NN}}(t<\bar{t})=$ $\Pi^{\mathrm{NN}}(t<\bar{t})-\Phi_{N}$ with

$\Pi^{\mathrm{NN}}(t<\bar{t}) \equiv 1+t^{2} / 9$.

When trade costs cross below $\bar{t}$, overall profits decline even if operating profits arising from exports increase. To be precise, the total sales $\left(q_{r 1}+q_{s 1}\right)$ remain constant when trade costs vary, but the average price declines because of fiercer price competition between the rivals. In addition, the differentiation between the two varieties produced by each firm is still at a minimum level. Thus, there is competition between two single-product exporters. The price competition between varieties produced by rivals is so aggressive that no firm finds it profitable to introduce an additional variety. In other words, each firm prefers to choose the largest differentiation with respect to the variety produced by its rival. Our result is similar to the findings by Martinez-Giralt and Neven (1988) showing that in a shopping model in which two firms supplying a homogeneous good and competing in price can select locations for two outlets in a linear city (in accordance with the traditional framework introduced in Hotelling, 1929), each rival prefers to eliminate one of its outlets and to be maximally differentiated from its rival. Similar mechanisms are at work in our model. ${ }^{8}$

b. When trade costs are sufficiently high $(t>\bar{t})$, the maximum differentiation between varieties produced by rivals does not hold. Indeed, in Appendix B we show that $\mathrm{d} \pi_{\mathrm{A}} / \mathrm{d} x_{2}>0$ and that $\mathrm{d} \pi_{\mathrm{B}} / \mathrm{d} x_{3}<0$ when $x_{1}^{*}=x_{2} / 3$ and $x_{4}^{*}=\left(2+x_{3}\right) / 3$ once $t>\bar{t}$. In other words, the cannibalization effect shrinks with high trade costs. By taking advantage of the protection it enjoys in its domestic market, each firm produces a second variety. High trade costs relax inter-firm competition that allows for product differentiation across varieties produced by a firm and causes prices to rise. Thus, the market expansion effect associated with the production of a second variety becomes stronger than the cannibalization effect when trade integration is weak.

\footnotetext{
${ }^{8}$ Note also that the principle of reciprocal dumping, as described in Brander and Krugman (1983), is still valid when oligopolistic firms become multi-product firms. Each firm has a smaller markup for each variety in its export market than at home. However, for each variety, the difference between the f.o.b. price for exports and the domestic price is less than trade costs, and this difference is not affected by the intrafirm product differentiation.
} 
However, given constraints (8) and (9) as well as equilibrium prices when both firms export at least one variety (provided in Appendix A.1), the best strategy of each firm maximizing its profit is to set the characteristics of products such that $p_{\mathrm{F} 2}^{*}=t$ and $p_{\mathrm{H} 3}^{*}=t$ when $t>\bar{t}$ so that $x_{2}^{*}=1 / 2-t / 6$ and $x_{3}^{*}=1 / 2+t / 6$ when $t>\bar{t}$. In Appendix B, we show that the configuration where $\left\{x_{1}^{*}=x_{2} / 3, x_{2}^{*}=1 / 2-t / 6\right\}$ and $\left\{x_{3}^{*}=1 / 2+t / 6, x_{4}^{*}=\left(2+x_{3}\right) / 3\right\}$ is a stable equilibrium. Under these circumstances, varieties 2 and 3 are not exported. Remember that we consider the regime under which both firms export at least one variety. Hence, once $x_{2}=x_{2}^{\max }$ and $x_{3}=x_{3}^{\max }$, each firm produces two varieties and exports a single variety. This outcome is a corner solution under this regime.

The equilibrium prices of each variety for each destination produced by firm A are now as follows:

$p_{\mathrm{H} 1}^{*}=1+t / 3+\left(x_{2}^{*}\right)^{2} / 2-2 x_{2}^{*}, p_{\mathrm{H} 2}^{*}=1+t / 3-2 x_{2}^{*}$, and $p_{\mathrm{F} 1}^{*}$ $=p_{\mathrm{H} 1}^{*}+t / 3$,

The introduction of a new variety by each rival reduces the equilibrium prices ( $\mathrm{dd} p_{\mathrm{H} 1}^{*} / \mathrm{d} x_{2}^{*}<0$ and $\mathrm{dd} p_{\mathrm{H} 2}^{*} / \mathrm{d} x_{2}^{*}<0$ for all admissible values of $x_{2}^{*}$ ). In addition, using the equilibrium prices (see Appendix A.1) and the levels of demand (see Eqs. (2) and (3)), the market share of firm A in its domestic country (country $\mathrm{H}$ ) is given by $q_{\mathrm{H} 1}^{*}+q_{\mathrm{H} 2}^{*}=1 / 2+t /[6(1-$ $\left.\left.2 x_{2}^{*}\right)\right]$ when $t>\bar{t}$ and by $(1+t / 3) / 2$ when $t<\bar{t}$. Similar results hold for firm B. Consequently, the production of a new variety by a firm raises its domestic market share (because $\left.1 / 2+t /\left[6\left(1-2 x_{2}^{*}\right)\right]>(1+t / 3) / 2\right)$ and, by symmetry, reduces its market share in the foreign country. Thus, the market expansion effect due to the introduction of a new variety prevails only in the domestic market.

Using equilibrium outputs $\left(x_{1}^{*}=x_{2}^{*} / 3, x_{3}^{*}=1-x_{2}^{*}\right.$, and $\left.x_{4}^{*}=\left(3-x_{2}^{*}\right) / 3\right)$ and equilibrium prices (16), the profit of each firm when is given by $\hat{\Pi}^{\mathrm{NN}}(t>\bar{t})-\Phi_{N}$ with

$\hat{\Pi}^{\mathrm{NN}}(t>\bar{t}) \equiv 1+\frac{t^{2}}{9\left(1-2 x_{2}^{*}\right)}+\frac{8\left(x_{2}^{*}\right)^{3}}{27}-2 x_{2}^{*}$

where $\hat{\Pi}^{\mathrm{NN}}(t>\bar{t}) \in\left(1,1+t^{2} / 9\right)$ when $t_{\max }^{\mathrm{NN}}>t>\bar{t}$. We can verify that $\partial \Pi^{\mathrm{NN}} / \partial x_{2}^{*}<0$. Note that the configuration where both firms are multiproduct producers corresponds to a prisoner's dilemma. Indeed, in presence of high trade costs, each firm finds optimal to adopt a multiproduct strategy, even though firms can earn higher profits when they supply a single product (see Appendix B). The gains associated with a higher domestic market share because of the introduction of a new variety does not offset the losses that result from lower prices and a lower market share in the foreign country.

It is worth mentioning that we consider the regime under which both firms export at least one variety. Under this regime, each firm produces two varieties and exports a single variety when trade costs are high enough. We show in Appendix $B$ that the outcome with $x_{2}=x_{2}^{\max }$ and $x_{3}=x_{3}^{\max }$ is locally stable. However, we do not know a priori whether this equilibrium yields the global profit maximum when trade costs reach high values. As a result, we should characterize the different equilibria under the regime where both firms export at most one variety (associated with different pricing policies) and then compare the profits reached under the two regimes (firms export at least one variety versus firms export at most one variety). ${ }^{9}$ We do not provide the equilibrium outcomes when firms export at most one variety because it would make the algebra more cumbersome without adding much to the analysis. Indeed, equilibria under both regimes share the same properties: each firm exports and produces two varieties when trade costs are high enough. Hence, even though the local equilibrium $\left\{x_{1}^{*}=x_{2} / 3\right.$, $\left.x_{2}^{*}=1 / 2-t / 6\right\}$ and $\left\{x_{3}^{*}=1 / 2+t / 6, x_{4}^{*}=\left(2+x_{3}\right) / 3\right\}$ is not a global maximum, our findings hold whether we consider the equilibrium outcome when both firms export at most one variety. Indeed, whatever the regime, the firms become multi-product when trade costs are high enough and profits increase with admissible values of trade costs.

To summarize,

Proposition 1. Assume that each firm exports to serve the foreign market. When trade costs are high enough, each firm is multi-product firm. When trade costs are low, both rivals are single-product firms. Regardless of trade costs, each rival exports one variety.

Hence, when firms export, high trade costs favor the emergence of multi-product firms. High tariff barriers distort competition, and therefore the cannibalization effect is weak. In this context, each firm has an incentive to adopt a multi-product strategy because the increase in domestic revenues is greater than the decline in revenues from foreign sales. However, when trade costs shrink, the cannibalization effect becomes stronger than the market-expansion effect, and therefore varieties supplied by the same producer become less differentiated. When trade costs become sufficiently low, firms become single-product producers.

\subsection{Firms are multinational (MM-type)}

We now consider the case in which each firm is a multinational. A second plant is now located abroad. At most, four varieties can be produced. In this case, there is no trade because the same variety is produced in both countries. The expressions of the profits are now given by:

$\pi_{\mathrm{A}}^{\mathrm{MM}}(t)=p_{\mathrm{H} 1} q_{\mathrm{H} 1}+p_{\mathrm{F} 1} q_{\mathrm{F} 1}+p_{\mathrm{H} 2} q_{\mathrm{H} 2}+p_{\mathrm{F} 2} q_{\mathrm{F} 2}-\Phi_{\mathrm{M}}$
$\pi_{\mathrm{B}}^{\mathrm{MM}}(t)=p_{\mathrm{H} 3} q_{\mathrm{H} 3}+p_{\mathrm{F} 3} q_{\mathrm{F} 3}+p_{\mathrm{H} 4} q_{\mathrm{H} 4}+p_{\mathrm{F} 4} q_{\mathrm{F} 4}-\Phi_{\mathrm{M}}$.

The equilibrium prices are given in Appendix A.2. Because there is no international trade, the equilibrium prices do not depend on trade costs. The differentiation of firm $A$ 's profit with respect to $x_{1}$ is given by (10) up to a constant and therefore $x_{1}^{*}=x_{2} / 3$ holds. Using $x_{1}^{*}$, we have

$\left.\frac{\mathrm{d} \pi_{\mathrm{A}}^{\mathrm{MM}}}{\mathrm{d} x_{2}}\right|_{x_{1}=x_{1}^{*}}=\frac{-\left(2+x_{3}+x_{2}\right)\left(2+3 x_{2}-x_{3}\right)}{18}<0$

and $d^{2} \pi_{A} / d x_{2}^{2} \leq 0$. Hence, we get $x_{2}^{*}=0$. Similarly, for firm $B$, differentiation of the profit function with respect to $x_{4}$ is given by (11) up to a constant, implying $x_{4}^{*}=\left(2+x_{3}\right) / 3$. Furthermore, we have

$\left.\frac{\mathrm{d} \pi_{\mathrm{B}}^{\mathrm{MM}}}{\mathrm{d} x_{3}}\right|_{x_{4}=x_{4}^{*}}=\frac{\left(4-x_{3}-x_{2}\right)\left(4+x_{2}-3 x_{3}\right)}{18}>0$

and $\mathrm{d}^{2} \pi_{\mathrm{B}} / \mathrm{d} x_{3}^{2} \leq 0$ so that $x_{3}^{*}=1$. As a consequence, the Nash perfect equilibrium corresponds to $x_{1}^{*}=x_{2}^{*}=0$ and $x_{3}^{*}=x_{4}^{*}=1$ whereas equilibrium prices are given by $p_{r i}^{*}=1$. Hence, under cross-hauling FDI, the differentiation between the two varieties produced by each firm is set at a minimum $\left(x_{1}^{*}=x_{2}^{*}\right.$ and $\left.x_{3}^{*}=x_{4}^{*}\right)$. Regarding low trade costs, each firm adopts a single-product strategy because of the fierce price competition between varieties produced by rival firms. The equilibrium profits then are expressed as follows:

\footnotetext{
${ }^{9}$ Note that, in Appendix B, we consider the case where only one firm exports at most one variety while its rival exports at most two varieties in order to check the stability of configuration $x_{2}=x_{2}^{\max }$ and $x_{3}=x_{3}^{\max }$.
}

$\pi_{\mathrm{A}}^{\mathrm{MM}}=1-\Phi_{N}-\Gamma=\pi_{\mathrm{B}}^{\mathrm{MM}}$ 
To summarize,

Proposition 2. Assume that both firms are multinational. Whatever the level of trade costs, each firm is a single-product firm, and the principle of maximum differentiation holds.

Note that the operating profits in each market are identical for each firm. However, in our framework, the fixed cost associated with the domestic production is lower than the fixed cost associated with the foreign production. Hence, each firm accepts a smaller profit for each unity of a variety produced abroad than for a variety produced at home. Thus, the two-way FDI can be viewed as reciprocal FDI dumping, in the sense of Baldwin and Ottaviano (2001).

\subsection{Asymmetric configuration (MN-type)}

Now we assume that only one firm exports to serve the foreign country (say, firm A, without loss of generality) so that varieties 1 and 2 are exclusively produced in country $\mathrm{H}$, whereas the other firm (firm B) is multinational. The two countries are linked only by exports of varieties produced by firm A from country $\mathrm{H}$ to country $\mathrm{F}$. However, this case is more complex because the multinational firm has two options giving rise to two types of product competition. First, the multinational supplies the same varieties in all countries. In this case, the profit function of firm A is given by Eq. (6) and for firm $B$, the profit function is given by Eq. (19). Second, the multinational can choose to supply one variety for each market which differs across the countries (one variety per country). In the following, we consider the latter type of product competition because it is the more profitable option for the multinational. Supplying a different variety in each country allows the multinational firm to exploit in a better way its market power in country $\mathrm{F}$ (this firm is the single producer located in country F) and to relax inter-firm competition prevailing in country $\mathrm{H}$. The results concerning the first option are reported in Appendix C.

Let $x_{\mathrm{B}}^{\mathrm{H}}$ (resp., $x_{\mathrm{B}}^{\mathrm{F}}$ ) be the variety produced by firm $\mathrm{B}$ (i.e., the multinational) in country $\mathrm{H}$ (resp., country $\mathrm{F}$ ) to serve exclusively that country. Hence, we must have $1 \geq x_{\mathrm{B}}^{\mathrm{H}} \geq x_{2} \geq x_{1} \geq 0$ and $1 \geq x_{\mathrm{B}}^{\mathrm{F}} \geq x_{2} \geq x_{1} \geq 0$. Note that we can have $x_{\mathrm{B}}^{\mathrm{H}} \lesseqgtr x_{\mathrm{B}}^{\mathrm{F}}$. Under the asymmetric configuration, the expression of the profit of firm $A\left(\pi_{\mathrm{A}}^{\mathrm{NM}}\right)$ is given by (6) and by

$\pi_{\mathrm{B}}^{\mathrm{NM}}=p_{\mathrm{B}}^{\mathrm{H}} q_{\mathrm{B}}^{\mathrm{H}}+p_{\mathrm{B}}^{\mathrm{F}} q_{\mathrm{B}}^{\mathrm{F}}$

for firm B where $p_{\mathrm{B}}^{r}$ (resp., $q_{\mathrm{B}}^{r}$ ) is the price (quantity) of variety produced and supplied in country $r$. The profit-maximizing prices are given in Appendix A.3. The equilibrium prices are not affected by trade costs in country $H$. For the same reasons explained in Section 3.2, the competition within country $\mathrm{H}$ is fierce.

The expression of $\mathrm{d} \pi_{\mathrm{A}}^{\mathrm{NM}} / \mathrm{d} x_{1}$ is given by (10) so that $x_{1}^{*}=x_{2} / 3$ regardless of $x_{\mathrm{B}}^{\mathrm{H}}$ and $x_{\mathrm{B}}^{\mathrm{F}}$ whereas

$\frac{\mathrm{d} \pi_{\mathrm{B}}^{\mathrm{NM}}}{\mathrm{d} x_{\mathrm{B}}^{\mathrm{H}}}=\frac{\left(4-x_{\mathrm{B}}^{\mathrm{H}}-x_{2}\right)\left(4+x_{2}-3 x_{\mathrm{B}}^{\mathrm{H}}\right)}{18}$

which is positive regardless of $x_{\mathrm{B}}^{\mathrm{H}}$ and $x_{2}$ so that $x_{B}^{H *}=1$ whatever $x_{1}$ and $x_{2}$. In Appendix D, we show that $x_{1}^{*}=x_{2}^{*}=0$ is an equilibrium so that maximum product differentiation between rival varieties produced in country $H$ is still prevalent $\left(x_{2}^{*}=0\right.$ and $\left.x_{\mathrm{B}}^{\mathrm{H}}=1\right) .{ }^{10}$

By contrast, in country $\mathrm{F}$, the multinational firm has a strong incentive to produce a country-specific variety because its homeproduced variety is thereby shielded from the cannibalization effect

\footnotetext{
${ }^{10}$ We obtain the same result with the regime where firm A exports at most one variety.
}

of its foreign-produced variety. The details of calculations are provided in Appendix D. Concerning the variety produced by the multinational firm and consumed exclusively in its home market (country F), we have

$\frac{\mathrm{d} \pi_{\mathrm{B}}^{\mathrm{NM}}}{\mathrm{d} x_{\mathrm{B}}^{\mathrm{F}}}=-\frac{\left[4 x_{\mathrm{B}}^{\mathrm{F}}+t-\left(x_{\mathrm{B}}^{\mathrm{F}}\right)^{2}\right]\left[-4 x_{\mathrm{B}}^{\mathrm{F}}+3\left(x_{\mathrm{B}}^{\mathrm{F}}\right)^{2}+t\right]}{18\left(x_{\mathrm{B}}^{\mathrm{F}}\right)^{2}}$

where $4 x_{\mathrm{B}}^{\mathrm{F}}+t-\left(x_{\mathrm{B}}^{\mathrm{F}}\right)^{2}>0$ when $x_{2}^{*}=0$.

(a) When trade costs reach low values $(t<1)$, it is straightforward to check that $x_{1}^{*}=x_{2}^{*}=0$ and $x_{\mathrm{B}}^{\mathrm{H}}=x_{\mathrm{B}}^{\mathrm{F}}=1$ is always an equilibrium for the second stage subgame. Low trade costs increase price competition so that firms become singleproduct firms and maximum differentiation prevails, even though asymmetry exists. Indeed, in this sub-case $(t<1)$, equilibrium prices are given by $p_{\mathrm{H} 1}^{*}=p_{\mathrm{B}}^{\mathrm{H}}=1, p_{F 1}^{*}=1+2 t / 3$ and $p_{\mathrm{B}}^{\mathrm{F}}=1+t / 3$ whereas expressions of equilibrium output are expressed as follows: $q_{\mathrm{H}}^{\mathrm{A}}=q_{\mathrm{H}}^{\mathrm{B}}=1 / 2, \quad q_{\mathrm{F}}^{\mathrm{A}}=(1-t / 3) / 2$ and $q_{\mathrm{F}}^{\mathrm{B}}=1-q_{\mathrm{F}}^{\mathrm{A}}$. As a result, equilibrium profits for firms $A$ and $B$ when $t<1$ are given by

$$
\begin{aligned}
& \pi_{\mathrm{A}}^{\mathrm{NMa}}=\left[1+(1-t / 3)^{2}\right] / 2-\Phi_{N}, \\
& \pi_{\mathrm{B}}^{\mathrm{NMa}}=\left[1+(1+t / 3)^{2}\right] / 2-\Phi_{M} .
\end{aligned}
$$

The operating profits are higher for the multinational firm because its domestic market $\mathrm{F}$ is protected by trade costs (firm A exports) while neither firm has an advantage in country $\mathrm{H}$. Consequently, the multinational has the same market share in country $\mathrm{H}$ as its rival firm, while its market share is higher in its home country.

b. When trade costs are intermediate $(4 / 3>t>1)$, although equilibrium prices and technical characteristics in country $\mathrm{H}$ are unchanged, the multinational firm supplies a new variety. The optimal technical characteristic of the variety supplied by the multinational in its domestic country is given by

$x_{\mathrm{B}}^{\mathrm{F}}(t)=2 / 3+\sqrt{4-3 t} / 3 \in[2 / 3,1]$

when $t \in[1,4 / 3]$ and the equilibrium price of this variety supplied is $p_{\mathrm{B}}^{\mathrm{F}}=\left(4 x_{\mathrm{B}}^{\mathrm{F}}(t)-x_{\mathrm{B}}^{\mathrm{F}}(t)^{2}+t\right) / 3$. Because firm $A$ has to pay trade costs for its exports to reach country $F$ while its rival does not incur trade costs, firm A produces and exports a single product $\left(x_{1}^{*}=x_{2}^{*}\right)$ and its characteristics are such as $x_{1}^{*}=0$. Hence, the general expression of equilibrium profits is as follows ${ }^{11}$ :

$\pi_{\mathrm{A}}^{\mathrm{NMb}}=\Pi_{\mathrm{A}}^{\mathrm{NMb}}-\Phi_{N}$,
$\pi_{\mathrm{B}}^{\mathrm{NMb}}=\Pi_{\mathrm{B}}^{\mathrm{NMb}}-\Phi_{M}$,

where

$$
\begin{aligned}
& \Pi_{A}^{N M b} \equiv \frac{1}{2}+\left(\frac{2 x_{B}^{F}(t)+x_{B}^{F}(t)^{2}}{3}-\frac{t}{3}\right)^{2} \frac{1}{2 x_{B}^{F}(t)}, \\
& \Pi_{\mathrm{B}}^{\mathrm{NMb}} \equiv \frac{1}{2}+\left(\frac{4 x_{\mathrm{B}}^{\mathrm{F}}(t)-x_{\mathrm{B}}^{\mathrm{F}}(t)^{2}}{3}+\frac{t}{3}\right)^{2} \frac{1}{2 x_{\mathrm{B}}^{\mathrm{F}}(t)} .
\end{aligned}
$$

Hence, when $t$ varies from 1 to $4 / 3, x_{3}^{*}(t)$ decreases, which results in an increase in the multinational firm's market share in its home

\footnotetext{
${ }^{11}$ Note that there is no discontinuity when the regime moves from case (a) to case (b). Indeed, when $t=4 / 3, x_{\mathrm{B}}^{\mathrm{F}}(t)=1$ and, thus, (25) $=(39)$ as well as $(26)=(40)$.
} 
country. As previously noted, increasing trade costs cause the multinational's market power to rise, which leads to a decline in the degree of product differentiation in country $\mathrm{F}$ but leaves the degree of product differentiation in country $\mathrm{H}$ unchanged.

(c) Finally, when trade costs become high enough ( $t>4 / 3$ ), we have $\mathrm{d} \pi_{\mathrm{B}}^{\mathrm{MN}} / \mathrm{d} x_{\mathrm{B}}^{\mathrm{F}}<0$. In this case, the multinational (firm $B$ ) has a strong incentive to increase differentiation among its own varieties $\left(x_{\mathrm{B}}^{\mathrm{F}}\right.$ converges to zero). However, there exists a limit value of $x_{\mathrm{B}}^{\mathrm{F}}$ (denoted by $\bar{x}_{\mathrm{B}}^{\mathrm{F}}$ ) below which no export of a variety produced by firm A occurs from country $\mathrm{H}$ to country $\mathrm{F}$. This threshold value is given by $\bar{x}_{\mathrm{B}}^{\mathrm{F}} \equiv \sqrt{1+t}-1$. Hence, when $x_{\mathrm{B}}^{\mathrm{F}}$ reaches $\bar{x}_{\mathrm{B}}^{\mathrm{F}}$, the multinational becomes the only supplier in its home market. However, this is a contestable monopoly in its domestic market $F$ because of the entry threat of firm $A$. The equilibrium price under this configuration is given by $2 x_{\mathrm{B}}^{\mathrm{F}} / 3+2 t / 3-2\left(x_{\mathrm{B}}^{\mathrm{F}}\right)^{2} / 3$. As a result, the equilibrium technical characteristic is given by $x_{\mathrm{B}}^{\mathrm{F}}=1 / 2$. In addition, because $1 / 2<\bar{x}_{\mathrm{B}}^{\mathrm{F}}$, firm $A$ is a single-product firm and does not export at equilibrium. Thus, equilibrium profits are given by

$\pi_{\mathrm{A}}^{\mathrm{NMc}}=1 / 2-\Phi_{N}$,

$\pi_{\mathrm{B}}^{\mathrm{NMc}}=1 / 2+(1 / 6+2 t / 3)-\Phi_{M}$

Hence, when $t>4 / 3$, the profits of the firm producing exclusively in its home country do not depend on trade costs because this firm cannot export. Such a result also occurs when rivals are multinationals. Hence, contrary to the assertion in Baldwin and Ottaviano (2001), the existence and the direction of trade are affected by foreign direct investments.

To summarize,

Proposition 3. Assume that one firm must export to serve a foreign country while another firm is a multinational. When trade costs are low enough $(t<1)$, both firms are single-product firms. When trade costs become sufficiently high $(t>1)$, the multinational becomes a multiproduct firm while its rival remains a single-product firm. In addition, trade is unilateral when $1<t<4 / 3$ and no trade occurs when $t>4 / 3$.

\section{Exports vs. FDI}

\subsection{Nash equilibrium (stage one)}

In this section, we first determine the subgame perfect Nash equilibria or, equivalently, when it is optimal for firms to become multinational or national. ${ }^{12}$ Three types of subgame perfect Nash equilibria can emerge: (i) both firms are multinational, (ii) both firms export from their home country or (iii) one firm is multinational while its rival produces exclusively for its domestic market. The type of equilibrium depends on trade costs $(t)$ and the multinationalization cost $(\Gamma)$. Details regarding the conditions under which such equilibria emerge are presented below.

(i) both firms are multinational (or two-way FDI) if and only if $1-\Gamma>\Pi_{A}^{M N k}$ with $k=\{a, b, c\}$ (see subsection 3.3). Three sub-cases have to be distinguished to determine the conditions under which each firm produces in both countries: (a) $t \leq 1$, (b) $1<t<4 / 3$, (c) $4 / 3 \leq t$. The configuration in which both firms are multinational (MM-type) is a subgame perfect Nash equilibrium if and only if

$\Gamma<t / 3-t^{2} / 18 \equiv \Gamma_{\mathrm{a}}^{\mathrm{M}}$ when $t \leq 1$

$\Gamma<1-\Pi_{\mathrm{A}}^{\mathrm{MNb}} \equiv \Gamma_{\mathrm{b}}^{\mathrm{M}}$ when $4 / 3>t>1$

$\Gamma<1 / 2 \equiv \Gamma_{\mathrm{c}}^{\mathrm{M}}$ when $t \geq 4 / 3$ where $\Gamma_{\mathrm{k}}^{\mathrm{M}}$ (with $k=a, b, c$ ) depends only on $t$. Note that $\Gamma_{\mathrm{b}}^{\mathrm{M}}=\Gamma_{\mathrm{a}}^{\mathrm{M}}$ when $t=1$ because $x_{\mathrm{B}}^{\mathrm{F}}(1)=1$, that $\Gamma_{\mathrm{b}}^{\mathrm{M}}$ increases with $t$ when $4 / 3>t>1$, and that $\Gamma_{\mathrm{b}}^{\mathrm{M}}=1 / 2$ when $t=4 / 3$ (see Fig. 1 ). Hence, the threshold value of $\Gamma$ below which two-way FDI occurs does not display any discontinuity. When $t<4 / 3$, the more trade costs decline, the less likely it is for the MM configuration in which each firm is a multinational to be a perfect Nash equilibrium. However, when trade costs are high $(t \geq 4 / 3)$, the existence of two-way FDI does not depend on the level of trade costs. There are two reasons for this result. First, when both firms are multinational, neither firm exports, and therefore equilibrium prices and outputs are unaffected by trade costs. Second, when one firm decides to produce exclusively in its home country, even though its rival is a multinational, the former firm does not export when $t>4 / 3$, and therefore its profits also do not depend on trade costs (see Section 3.3).

(ii) Both firms only produce in their home country if and only if $\Pi^{\mathrm{NN}}(t)>\Pi_{\mathrm{B}}^{\mathrm{MNk}}-\Gamma$ where $\Pi_{\mathrm{B}}^{\mathrm{MNk}}$ corresponds to the operating profits when a firm becomes multinational while its rival exports (see Section 3.3). More precisely, we have a Nash equilibrium in which both firms export from their home country if and only if

$$
\begin{array}{lc}
\Gamma>t / 3-t^{2} / 18 \equiv \Gamma_{\mathrm{a}}^{\mathrm{N}} & \text { when } 1 \geq t \\
\Gamma>\Pi_{\mathrm{B}}^{\mathrm{MNb}}-\left(1+t^{2} / 9\right) \equiv \Gamma_{\mathrm{b}}^{\mathrm{N}}>0 & \text { when } 4 / 3>t>1 \\
\Gamma>2 / 3+2 t / 3-\Pi^{\mathrm{NN}}(t) \equiv \Gamma_{\mathrm{c}}^{\mathrm{N}}>0 & \text { when } t \geq 4 / 3
\end{array}
$$

where $\Gamma_{k}^{N}$ (with $k=a, b, c$ ) depends only on $t$. By inspection, we can check that $\Gamma_{b}^{N}$ and $\Gamma_{c}^{N}$ increase with trade costs. Note that we have $\Pi^{\mathrm{NN}}(t)=1+t^{2} / 9$ when $4 / 3 \leq t<\bar{t}$ and $\Pi^{\mathrm{NN}}(t)$ $\in\left[1,1+t^{2} / 9\right]$ when $t>\bar{t}$. Hence, when $t>4 / 3$, the limit value of $\Gamma$ above which both firms produce only in their home country depends on trade costs. This is not the case for the limit value of $\Gamma$ below which both firms are multinational (see Fig. 1). Finally, it is easy to confirm that $\Gamma_{\mathrm{a}}^{N}=\Gamma_{\mathrm{b}}^{N}$ when $t=1$ and $1 / 2>\Gamma_{\mathrm{c}}^{N}>\Gamma_{\mathrm{b}}^{N}$ when $t=4 / 3$. In addition, by inspection, we have $\Gamma_{\mathrm{c}}^{N}>1 / 2$ when $t=t^{\max }$ (see Fig. 1 ).

(iii) A single multinational firm (or one-way FDI). The configuration in which one firm is a multinational whereas its rival produces exclusively in its home country is a perfect Nash equilibrium if and only if $\Gamma_{\mathrm{c}}^{N}>\Gamma>\Gamma_{\mathrm{c}}^{M}=1 / 2$. Note that we have $\Gamma_{\mathrm{a}}^{N}=\Gamma_{\mathrm{a}}^{M}$ and that we can verify by inspection that $\Gamma_{\mathrm{b}}^{M}>\Gamma_{\mathrm{b}}^{N}$ because $\Gamma_{k}^{\mathrm{N}}$ and $\Gamma_{k}^{\mathrm{M}}$ depend only on $t$. In other words, the asymmetric configuration is never an equilibrium as long as $t<4 / 3$. However, when $t=4 / 3$, we have $\Gamma_{\mathrm{c}}^{\mathrm{N}}<1 / 2$, and, by inspection, we get $\Gamma_{\mathrm{c}}^{\mathrm{N}}>1 / 2$ when $t=t^{\max }$. Hence, as $\Gamma_{\mathrm{c}}^{\mathrm{N}}$ increases with trade costs while $\Gamma_{\mathrm{c}}^{\mathrm{M}}=1 / 2$, there exists a range of trade costs for which $\Gamma_{\mathrm{c}}^{\mathrm{N}}>\Gamma_{\mathrm{c}}^{\mathrm{M}}$ (see Fig. 1). In this case of asymmetric equilibrium, one firm produces exclusively in its home country. The fact that its rival is a multinational signifies

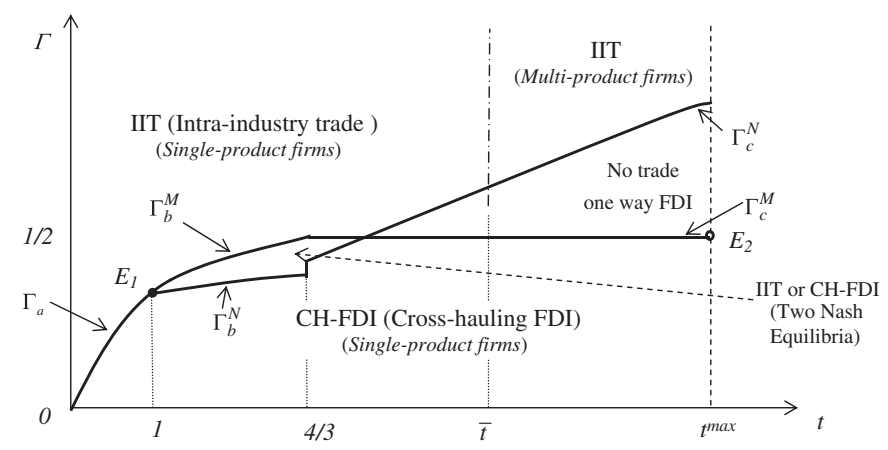

Fig. 1. FDI vs. exports

\footnotetext{
${ }^{12}$ We focus on the structure of equilibria when trade costs are not prohibitive.
} 
that the firm cannot increase its profits by producing abroad because of the high multinationalization costs $(\Gamma)$. As a result, the competition between the national firm and its rival is unbalanced in favor of the multinational. The multinational is a multi-product firm, and it behaves as a contestable monopoly in its home market, while its rival is single-product producer and does not export.

In summary and as illustrated in Fig. 1, we provide the following proposition.

Proposition 4. Cross-hauling FDI emerges when $\Gamma<\Gamma_{k}^{\mathrm{M}}$ and intraindustry trade occurs when $\Gamma>\Gamma_{k}^{\mathrm{N}}$. One-way FDI with no trade takes place with a multinational multi-product firm and a single-product firm when $\Gamma_{\mathrm{c}}^{\mathrm{N}}>\Gamma>\Gamma_{\mathrm{c}}^{\mathrm{M}}$.

\subsection{Discussion}

Some comments are in order. First, the fact that cross-hauling FDIs emerge if and only if trade costs are sufficiently high (see Fig. 1) corresponds to the usual tariff jumping argument advanced by many theoretical models on horizontal FDI. However, our analysis shows that two-way FDI arises from a prisoner's dilemma game. Profit levels are higher when both firms export than when they are both multinationals. Comparisons between (22) and (15) or (17) show that operating profits are higher when firms export regardless of trade costs. Price competition is lower when rivals produce exclusively in their own country. Moreover, MNFs incur additional fixed costs $(\Gamma)$ in setting up a subsidiary abroad. ${ }^{13}$ Despite the fact that the outcome when both rivals export leads to the highest levels of profits, it is rational for each firm to set up a second plant producing the same variety abroad to preserve its profitability. If a firm becomes a multinational, price competition increases (via tariff jumping), and access for exporters to the foreign market becomes more difficult. This, in turn, triggers entry of new multinationals. ${ }^{14}$ The export strategy is strictly dominated by the multinational strategy, leading to fierce price competition. The market outcome when both firms are multinational is, therefore, not Pareto optimal.

Second, even if the countries are identical ex-ante and the firms all have access to the same technology, an asymmetric outcome can emerge when one firm becomes a multi-product multinational while its rival is a single-product firm and is unable to profitably export. To the best of our knowledge, the existing theoretical literature shows that intra-industry FDI, either in homogeneous or differentiated products, is two-way FDI. With the framework developed in this paper, we can show that one-way FDI without exports can emerge even if firms share the same technology and countries are identical. Such a configuration arises when trade costs and multinationalization costs are high enough. High trade costs give both firms a strong incentive to produce abroad, leading to higher profits. However, when one firm becomes a multinational, its rival prefers to produce only in its home country because the increase in operating profits that the latter would be able to obtain by producing abroad is less than the cost of multinationalization. Hence, this configuration is equivalent to a chicken game in which, at the two perfect Nash equilibria, there is one-way FDI and no trade occurs.

Third, as long as $\Gamma>1 / 2$, the relationship between trade flows and trade costs is non-linear (see Fig. 1). Intra-industry trade can occur when trade costs are high enough. This result may explain why the empirical relationship between trade costs and FDI is not clear-cut. For example, Brainard (1997) and Ekholm (1997) by using a probit

\footnotetext{
13 This result differs from the result obtained by Baldwin and Ottaviano (2001). That study shows that under certain conditions, it is possible for profits to reach their highest levels when both firms are multinational. However, when product differentiation is endogenous, profits are always higher if both firms export.

${ }^{14}$ Behrens and Picard (2008) obtain a similar result but from a different model.
}

model show that there is no significant positive relationship between trade costs and the probability of establishing affiliates abroad. ${ }^{15}$ Neary (2009) proposes two explanations. First, the countries that host foreign plants may be export platforms that serve several other countries belonging to the same trading bloc. Second, low trade costs favor crossborder mergers, which are quantitatively more important than greenfield FDI. Our explanation is based on the fact that firms are multi-product firms and their strategies affect the degree of product differentiation. Each rival may prefer to export two products from its home country rather than to adopt a multinational structure for the following reason. By serving a foreign country only through exports, the firms would benefit from the asymmetric competition that results from high trade barriers. By contrast, cross-hauling FDI implies that MNFs are single-product producers and that price competition is fierce. If we had assumed that firms were exclusively single-product firms, high trade barriers would have favored FDIs, as shown by Mathieu (1997). In that case, $E_{1}$ and $E_{2}$ would have merged as a single area in Fig. 1. This shows that higher trade barriers do not necessarily trigger foreign direct investments.

\subsection{Robustness of results}

Our results hold even if we allow for a cost of product differentiation by introducing a positive additional fixed cost associated with the production of new variety (assuming, as in the case of all types of fixed costs, that this cost is not too high). The conditions under which a stable outcome could emerge from both firms adopting a multinational structure do not depend on an additional fixed cost associated with the production of new variety (i.e., $\Gamma_{\mathrm{k}}^{\mathrm{M}}$ would be unchanged). The two firms are single-product producers when both firms produce abroad and also when one firm exports while its rival is a multinational. In addition, the conditions for the stability of the equilibrium in which both firms export do not depend on additional fixed costs associated with the production of new variety when trade costs are low or high. When $t>\bar{t}$ (resp., $t<1$ ), firms produce two varieties (resp., one variety) when both firms export, and the multinational produces two varieties (resp., one variety) when its rival exports to serve the foreign market (see subsection 3.3). Hence, in this case, the fixed cost associated with a new variety does not change the conditions for stability. When trade costs take intermediate values $(\bar{t}>t>1)$, the configuration in which both firms export is more likely to occur when there is a positive additional fixed cost associated with a new variety. In this case, $\Gamma_{\mathrm{b}}^{\mathrm{N}}$ and $\Gamma_{\mathrm{c}}^{\mathrm{N}}$ would be lower over the interval $1<t<\bar{t}$. However, the results would be qualitatively identical.

We have assumed that no intra-firm trade occurs inside the horizontal multinationals. However, this assumption may be challenged when firms are potentially multi-product firms. Following Baldwin and Ottaviano (2001), we could allow for the possibility that the MNF decides to produce one variety abroad and then exports a positive share of its foreign production to serve its own domestic market. Such a configuration was examined in the working paper version of this paper (Blanchard et al., 2010). In the working paper version, we show, at the equilibrium, that the MNF produces the same product at home and abroad to avoid trade costs (tariff jumping argument). Hence, when cross-hauling FDI occurs, no intra-firm (or intra-industry) trade takes place, even though firms may produce a different variety in a foreign country. ${ }^{16}$ This result allows us to

\footnotetext{
${ }^{15}$ However, empirical studies on the relative importance of foreign activities show that trade costs do have a positive effect on the share of FDI in the sum of affiliates' sales plus exports (see Navaretti and Venables, 2004, and Blanchard et al., 2007).

${ }^{16}$ Baldwin and Ottaviano (2001) show that intra-industry trade and cross-hauling horizontal FDI can be complements by developing a model in which two multi-product firms provide four varieties that are imperfectly substitutable. Because, by assumption, households consume all varieties, international trade occurs automatically when twoway FDI takes place. In our study, when the degree of product differentiation is treated as a strategic variable, horizontally integrated multinational corporations do not appear to simultaneously undertake both cross-hauling FDI and intra-industry trade between the parent and its affiliates.
} 
generalize the well-known principle of the standard literature that exports and FDI are substitutes. In addition, we show in the working paper version, under the asymmetric perfect Nash equilibrium with one-way FDI, that the multinational produces two varieties (one per country) and does not export (no intra-firm trade occurs). This is the best strategy for the multinational because this allows the firm to limit the cannibalization effect between its varieties and to also avoid trade costs.

Finally, we discuss whether our results are sensitive to the choice of the product differentiation model. Our approach is based on the "linear city" model, but it might be worthwhile to consider the extent to which our results would be different if we adopted a "circular city" model. The effects of competition in the circular city model differ from the linear city model because the former configuration does not allow for a captive demand. However, the results are qualitatively identical. When both firms are multinational, the equilibria in which each firm is a single-product firm and product differentiation is set at the maximum level are not challenged. In the case in which one firm is a multinational while its rival produces exclusively in its domestic country, the multinational produces the same variety at home and abroad as long as its rival export. However, when trade costs are high enough, the multinational becomes a monopoly in its domestic market, and it also becomes a multi-product firm (with one different variety per country) to benefit from its domestic market power. When both firms export and produce only at home, both firms are singleproduct firms and the maximum differentiation occurs. as long as $0<t<\sqrt{3} / 4$. When $\sqrt{3} / 4<t$, it is profitable for each firm to produce a second variety. Hence, as in the linear city model, high trade costs lead to an increase in the product ranges of firms. However, in the circular city model, the presence of multi-product firms is possible even at lower values of trade costs. In comparison with the linear city model, we obtain a lower threshold value of trade costs above which both exporters become multi-product firms. This suggests that without captive demand, trade costs have a stronger effect on the distortion of competition in favor of the local firm.

\section{Concluding remarks}

By considering product differentiation as a strategic variable for large firms, we shed new light on the interaction between the production abroad and the firms' product range. Even when technology has the same productivity for each variety, firms drop some varieties when there is trade integration. We have also shown that each rival firm may prefer to export its varieties when trade costs are high rather than to shift production of one variety abroad. Our analysis also suggests that two-way FDI can be modeled as a prisoner's dilemma game. Even though the configuration in which firms export is a Pareto optimal outcome, each firm produces in both countries when trade costs take intermediate values. Finally, when trade costs are low enough, firms export and produce a single variety. Such findings show that economic integration via trade or FDI reduces the product range available to consumers. Furthermore, the relationship between trade costs and the decision to produce abroad is non-linear. Endogenous product differentiation plays a central role in the explanations of our results.

Two extensions from our trade-FDI model with endogenous product differentiation should be considered. First, a welfare analysis should be conducted because the gains from trade integration in our study are ambiguous. On the one hand, the number of varieties available in each country declines when trade costs fall. On the other hand, trade liberalization contributes to lower prices. Second, room exists for the customization of product ranges for foreign markets. We have assumed that each rival has a world product range or, equivalently, that it offers the same varieties in its home markets and in foreign markets. It would be interesting to analyze firms' internationalization strategy if they were able to adapt their product range to the specific conditions of each country in terms of competition and also in terms of their customers' requirements. It would be interesting to consider that the unit cost of differentiation supported by the consumers who do not consume their ideal product may be different from one (as it is assumed in our paper) and that this unit cost may be not the same for exports and domestic varieties.

\section{Appendix A. Equilibrium prices (stage 3)}

1. Under NN-configuration, the profit maximizing prices for firms A and $\mathrm{B}$ are given by

$p_{\mathrm{H} 1}=\frac{t}{3}-\frac{1}{2} x_{1}^{2}+\frac{1}{6} x_{2}^{2}-\frac{2}{3} x_{2}+\frac{1}{3} x_{3}^{2}+\frac{2}{3} x_{3}$

$p_{\mathrm{H} 2}=\frac{t}{3}-\frac{1}{3} x_{2}^{2}-\frac{2}{3} x_{2}+\frac{1}{3} x_{3}^{2}+\frac{2}{3} x_{3}$

$p_{\mathrm{F} 1}=\frac{2 t}{3}-\frac{1}{2} x_{1}^{2}+\frac{1}{6} x_{2}^{2}-\frac{2}{3} x_{2}+\frac{1}{3} x_{3}^{2}+\frac{2}{3} x_{3}$

$p_{\mathrm{F} 2}=\frac{2 t}{3}-\frac{1}{3} x_{2}^{2}-\frac{2}{3} x_{2}+\frac{1}{3} x_{3}^{2}+\frac{2}{3} x_{3}$

and

$$
\begin{aligned}
& p_{\mathrm{F} 3}=\frac{t}{3}+\frac{1}{3} x_{2}^{2}-\frac{4}{3} x_{2}-\frac{1}{3} x_{3}^{2}+\frac{4}{3} x_{3} \\
& p_{\mathrm{F} 4}=\frac{t}{3}+\frac{1}{3} x_{2}^{2}-\frac{4}{3} x_{2}+\frac{1}{6} x_{3}^{2}+\frac{1}{3} x_{3}-\frac{1}{2} x_{4}^{2}+x_{4} \\
& p_{\mathrm{H} 3}=\frac{2 t}{3}+\frac{1}{3} x_{2}^{2}-\frac{4}{3} x_{2}-\frac{1}{3} x_{3}^{2}+\frac{4}{3} x_{3} \\
& p_{\mathrm{H} 4}=\frac{2 t}{3}+\frac{1}{3} x_{2}^{2}-\frac{4}{3} x_{2}+\frac{1}{6} x_{3}^{2}+\frac{1}{3} x_{3}-\frac{1}{2} x_{4}^{2}+x_{4}
\end{aligned}
$$

2. Under MM-configuration, the profit maximizing prices for firm $\mathrm{A}$ and $\mathrm{B}$ are given by

$$
\begin{aligned}
& p_{\mathrm{H} 1}=p_{\mathrm{F} 1}=-\frac{x_{1}^{2}}{2}+\frac{x_{2}^{2}}{6}-\frac{2 x_{2}}{3}+\frac{x_{3}^{2}}{3}+\frac{2 x_{3}}{3} \\
& p_{\mathrm{H} 2}=p_{\mathrm{F} 2}=-\frac{x_{2}^{2}}{3}-\frac{2 x_{2}}{3}+\frac{x_{3}^{2}}{3}+\frac{2 x_{3}}{3} \\
& p_{\mathrm{H} 3}=p_{\mathrm{F} 3}=\frac{x_{2}^{2}}{3}-\frac{4 x_{2}}{3}-\frac{x_{3}^{2}}{3}+\frac{4 x_{3}}{3} \\
& p_{\mathrm{H} 4}=p_{\mathrm{F} 4}=\frac{x_{2}^{2}}{3}-\frac{4 x_{2}}{3}+\frac{x_{3}^{2}}{6}+\frac{x_{3}}{3}-\frac{x_{4}^{2}}{4}+x_{4}
\end{aligned}
$$

3. Under MN-configuration, the profit maximizing prices for firm $A$ and $B$ are given by

$$
\begin{aligned}
& p_{\mathrm{H} 1}=\frac{\left(x_{\mathrm{B}}^{\mathrm{H}}\right)^{2}}{3}+\frac{2 x_{\mathrm{B}}^{\mathrm{H}}}{3}-\frac{x_{1}^{2}}{2}+\frac{x_{2}^{2}}{6}-\frac{2 x_{2}}{3} \\
& p_{\mathrm{H} 2}=\frac{\left(x_{\mathrm{B}}^{\mathrm{H}}\right)^{2}}{3}+\frac{2 x_{\mathrm{B}}^{\mathrm{H}}}{3}-\frac{x_{2}^{2}}{3}-\frac{2 x_{2}}{3} \\
& p_{\mathrm{B}}^{\mathrm{H}}=-\frac{\left(x_{\mathrm{B}}^{\mathrm{H}}\right)^{2}}{3}+\frac{4 x_{\mathrm{B}}^{\mathrm{H}}}{3}+\frac{x_{2}^{2}}{3}-\frac{4 x_{2}}{3}
\end{aligned}
$$


in country $H$ and by

$$
\begin{aligned}
& p_{\mathrm{F} 1}=\frac{2 t}{3}+\frac{\left(x_{\mathrm{B}}^{\mathrm{F}}\right)^{2}}{3}+\frac{2 x_{\mathrm{B}}^{\mathrm{F}}}{3}-\frac{x_{1}^{2}}{2}+\frac{x_{2}^{2}}{6}-\frac{2 x_{2}}{3} \\
& p_{\mathrm{F} 2}=\frac{2 t}{3}+\frac{\left(x_{\mathrm{B}}^{\mathrm{F}}\right)^{2}}{3}+\frac{2 x_{\mathrm{B}}^{\mathrm{F}}}{3}-\frac{x_{2}^{2}}{3}-\frac{2 x_{2}}{3} \\
& p_{\mathrm{B}}^{\mathrm{F}}=\frac{t}{3}-\frac{\left(x_{\mathrm{B}}^{\mathrm{F}}\right)^{2}}{3}+\frac{4 x_{\mathrm{B}}^{\mathrm{F}}}{3}+\frac{x_{2}^{2}}{3}-\frac{4 x_{2}}{3}
\end{aligned}
$$

in country $F$.

\section{Appendix B. Technical characteristics when both firms export}

Remember that, when both firms export at least one variety, we have $x_{1}^{*}=x_{2} / 3$ and $x_{4}^{*}=\left(2+x_{3}\right) / 3$ regardless of the technical characteristics set by the rival and the first order conditions associated with varieties 2 and 3 are given by

$\left.\frac{\mathrm{d} \pi_{\mathrm{A}}}{\mathrm{d} x_{2}}\right|_{x_{1}=x_{1}^{*}}=\frac{t^{2}}{9\left(x_{3}-x_{2}\right)^{2}}-\frac{4\left(1+2 x_{2}-x_{2}^{2}\right)-\left(x_{3}-x_{2}\right)^{2}}{9}$

and

$\left.\frac{\mathrm{d} \pi_{\mathrm{B}}}{\mathrm{d} x_{3}}\right|_{x_{4}=x_{4}^{*}}=-\frac{t^{2}}{9\left(x_{3}-x_{2}\right)^{2}}+\frac{4\left(2-x_{3}^{2}\right)-\left(x_{3}-x_{2}\right)^{2}}{9}$

In addition, remember that each firm exports at least one variety if and only if $p_{\mathrm{F} 2}-t \geq 0$ and $p_{\mathrm{H} 3}-t \geq 0$ (because $p_{\mathrm{F} 2} \leq p_{\mathrm{F} 1}$ and $p_{\mathrm{H} 3} \leq p_{\mathrm{H} 4}$ ) or, equivalently, $t \leq t_{2}^{\max }$ and $t \leq t_{3}^{\max }$ or, equivalently,

$x_{2} \leq x_{2}^{\max } \equiv \sqrt{1+x_{3}^{2}+2 x_{3}-t}-1$

$x_{3} \geq x_{3}^{\min }=2-\sqrt{4+x_{2}^{2}-4 x_{2}-t}$

Five types of configuration may emerge: (i) a corner solution with $x_{2}=x_{1}=0$ and $x_{3}=x_{4}=1$; (ii) an interior solution with $1>x_{3}>x_{2}>0$; (iii) the case where $1>x_{3}>x_{2}=0$ (or $1=x_{3} \geq x_{2}>0$, by symmetry); (iv) the case where $x_{3}=x_{3}^{\min }$ and $x_{2}^{\max }>x_{2}>0$ (or $x_{2}=x_{2}^{\max }$ and $1>x_{3}>x_{3}^{\min }$, by symmetry); (v) the case with $x_{2}=x_{2}^{\max }$ and $x_{3}=x_{3}^{\min }$.

In what follows, we determine whether each of the five configurations is an equilibrium. As we will show, only configurations (i) and (v) can be an equilibrium.

(i) The case where $x_{1}=x_{2}=0$ and $x_{3}=x_{4}=1$ is an equilibrium if and only if

$\left.\frac{\mathrm{d} \pi_{\mathrm{A}}}{\mathrm{d} x_{2}}\right|_{x_{1}=x_{2}=0, x_{3}=1}=-\left.\frac{\mathrm{d} \pi_{\mathrm{B}}}{\mathrm{d} x_{3}}\right|_{x_{3}=x_{4}=1, x_{2}=0}=\frac{t^{2}}{9}-\frac{1}{3}<0$.

Hence, when $t<\sqrt{3}$, the configuration where $x_{1}^{*}=x_{2}^{*}=0$ and $x_{3}^{*}=x_{4}^{*}=1$ is an equilibrium.

(ii) If the interior solution is an equilibrium $\left(1>x_{3}>x_{3}^{\min }\right.$ and $\left.x_{2}^{\max }>x_{2}>0\right)$, we must have $x_{2}^{*}$ and $x_{3}^{*}$ are such that or, equivalently,

$$
\begin{aligned}
\frac{t^{2}}{9\left(x_{3}-x_{2}\right)^{2}} & =\frac{4\left(1+2 x_{2}-x_{2}^{2}\right)-\left(x_{3}-x_{2}\right)^{2}}{9} \text { and } \frac{t^{2}}{9\left(x_{3}-x_{2}\right)^{2}} \\
& =\frac{4\left(2-x_{3}^{2}\right)-\left(x_{3}-x_{2}\right)^{2}}{9}
\end{aligned}
$$

In this case, we must have $1-x_{2}=x_{3}$. When $x_{3}=1-x_{2}$, then the first and second order conditions become

$\left.\frac{\mathrm{d} \pi_{\mathrm{A}}}{\mathrm{d} x_{2}}\right|_{x_{1}=x_{1}^{*}, x_{3}=1-x_{2}}=\frac{t^{2}-\Lambda\left(x_{2}\right)}{9\left(1-2 x_{2}\right)^{2}}$

$\left.\frac{\mathrm{d}^{2} \pi_{\mathrm{A}}}{\mathrm{d} x_{2}^{2}}\right|_{x_{1}=x_{1}^{*}, x_{3}=1-x_{2}}=\frac{t^{2}-\Lambda\left(x_{2}\right)}{9\left(1-2 x_{2}\right)^{3}}+\frac{t^{2}-\left(30 x_{2}^{2}-43 x_{2}+7\right)\left(1-2 x_{2}\right)^{2}}{9\left(1-2 x_{2}\right)^{3}}$

where $\Lambda\left(x_{2}\right) \equiv\left(-8 x_{2}^{2}+12 x_{2}+3\right)\left(1-2 x_{2}\right)^{2}$ with $\Lambda=3$ when $x_{2}=0$, $\Lambda=0$ when $x_{2}=1 / 2$ and $\Lambda$ decreases with $x_{2}$ when $x_{2}$ varies from 0 to $1 / 2\left(\mathrm{dd} \Lambda / \mathrm{d} x_{2}=-8 x_{2}\left(2 x_{2}-1\right)\left(8 x_{2}-11\right)\right)$. Because $\Lambda\left(x_{2}\right)<3$ regardless of $x_{2}$, no interior solution $\left(1>x_{3} \geq x_{2}>0\right)$ can be a Nash equilibrium when $t>\sqrt{3}$ because (B.4) is positive. In other words, firm $A$ have incentive to deviate from the interior solution in this case.

When $t<\sqrt{3}$, an interior solution exists if and only if three conditions hold: (a) $t^{2}-\Lambda\left(x_{2}^{*}\right)=0$ (see (B.4)); (b) $t^{2}-\left(30 x_{2}^{* 2}-43 x_{2}^{*}+7\right)(1-$ $\left.2 x_{2}^{*}\right)^{2}<0$ (see (B.5)); (c) $t<3\left(1-2 x_{2}^{*}\right.$ ) or, equivalently, $x_{2}^{*}<1 / 2-t / 6$ (note that similar conditions hold for firm $B$, by symmetry).

Note that if condition (a) is checked then condition (c) holds. Indeed, $t<3\left(1-2 x_{2}^{*}\right)$ is equivalent to $t^{2}<9\left(1-2 x_{2}^{*}\right)^{2}$. Because $-8 x_{2}^{2}+12 x_{2}+3<9$, we have $\Lambda\left(x_{2}^{*}\right)<9\left(1-2 x_{2}^{*}\right)^{2}$ so that $t^{2}-\Lambda\left(x_{2}^{*}\right)=0$ implies that $t<3\left(1-2 x_{2}^{*}\right)$.

In addition, if condition (a) holds, then condition ( $b$ ) is checked if and only if $\Lambda\left(x_{2}\right)<\left(30 x_{2}^{2}-43 x_{2}+7\right)\left(1-2 x_{2}\right)^{2}$ or, equivalently, $x_{2}<(55-\sqrt{2417}) / 76 \simeq 0.07$. Hence, because we must have $t^{2}-\Lambda\left(x_{2}^{*}\right)$ $=0$, there exists an interior solution if and only if $\sqrt{3}>t>1.66$ and $x_{2}^{*}<0.07$. However, this Nash equilibrium is not Pareto dominant contrary to the Nash equilibrium with $x_{2}=0$ and $x_{3}=1$. By using the fact that, at the equilibrium prices, the technical characteristics of varieties 1 and 4 maximizing the total profits $\left(\pi_{A}+\pi_{B} \equiv \pi_{T}\right)$ are given by $x_{1}=x_{2} / 3$ and $x_{4}=\left(2+x_{3}\right) / 3$. In addition, we can show that $x_{2}=0$ and $x_{3}=1$ maximize the sum of profits $\left(\pi_{A}+\pi_{B}\right)$. Indeed, we have,

$\left.\frac{\mathrm{d}^{2} \pi_{T}}{\mathrm{~d} x_{2}^{2}}\right|_{x_{1}=x_{1}^{*}, x_{3}=1-x_{2}}=\frac{4 t^{2}+\left(7 x_{2}+4\right)\left(1-2 x_{2}\right)^{3}}{9\left(1-2 x_{2}\right)^{3}}$

which is positive regardless of $x_{2}$ and therefore there is no interior solution. Furthermore,

$$
\begin{aligned}
& \pi_{T}(0,0,1,1)-\pi_{T}\left(x_{2}^{\max } / 3, x_{2}^{\max }, x_{3}^{\min },\left(x_{3}^{\min }+2\right) / 3\right) \\
& \quad=\frac{52}{27}+\frac{65}{324} t^{2}-\frac{34 t}{27}+\frac{t^{3}}{486}
\end{aligned}
$$

which is positive for all admissible values of $t(3 \geq t \geq 0)$. Hence, the total surplus of firms is maximized when they are single-product producers and when $x_{2}=x_{1}=0$ and $x_{3}=x_{4}=1$. Consequently, the configuration where firms are multiproduct may be a Nash equilibrium but it is never Pareto dominant.

(iii) The configuration with $1>x_{3}>x_{2}=0$ is an equilibrium if and only if

$\left.\frac{\mathrm{d} \pi_{A}}{\mathrm{~d} x_{2}}\right|_{x_{1}=x_{1}^{*}, x_{2}=0}<0$ and $\left.\frac{\mathrm{d} \pi_{B}}{\mathrm{~d} x_{3}}\right|_{x_{4}=x_{4}^{*}, x_{2}=0}=0$.

$\left.\frac{\mathrm{d} \pi_{\mathrm{A}}}{\mathrm{d} x_{2}}\right|_{x_{1}=x_{1}^{*}}=\left.\frac{\mathrm{d} \pi_{\mathrm{B}}}{\mathrm{d} x_{3}}\right|_{x_{4}=x_{4}^{*}}=0$ 
Some calculations show that the latter equality implies that $x_{3}^{*}=$ $\sqrt{20-5 \sqrt{16-5 t^{2}}} / 5$ with $1>x_{3}^{*}$ if and only if $t<\sqrt{3}$. Otherwise, when $t>\sqrt{3}, x_{3}^{*}<1$ cannot be an equilibrium. When $t<\sqrt{3}$, we have

$\left.\frac{\mathrm{d} \pi_{\mathrm{A}}}{\mathrm{d} x_{2}}\right|_{x_{1}=x_{1}^{*}, x_{2}=0, x_{3}=\sqrt{20-5 \sqrt{16-5 t^{2}} / 5}}=\frac{20\left(-16+5 t^{2}+4 \sqrt{16-5 t^{2}}\right)}{9 x_{3}^{3}}$

which is equal to zero if and only if $t=0$ and positive as long as $t \leq \sqrt{3}$. Hence, the configuration where $1>x_{3}>x_{2}=0$ cannot be an equilibrium regardless of $t \geq 0$.

(iv) The configuration $x_{3}=x_{3}^{\min }$ and $x_{2}^{\max }>x_{2}>0$ is an equilibrium if

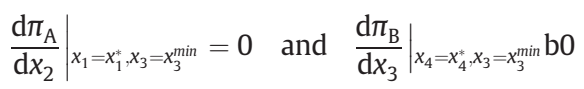

or, equivalently,

$\frac{t^{2}}{9\left(x_{3}^{\min }-x_{2}^{*}\right)^{2}}=\frac{\left[4\left(1+2 x_{2}^{*}-x_{2}^{* 2}\right)-\left(x_{3}^{\min }-x_{2}^{*}\right)^{2}\right]}{9}$
$\frac{t^{2}}{9\left(x_{3}^{\min }-x_{2}^{*}\right)^{2}}>\frac{\left[4\left(2-\left(x_{3}^{\min }\right)^{2}\right)-\left(x_{3}^{\min }-x_{2}^{*}\right)^{2}\right]}{9}$

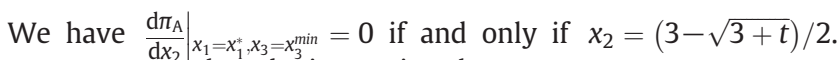
However, we can show by inspection that

$\left.\frac{\mathrm{d}^{2} \pi_{\mathrm{B}}}{\mathrm{d} x_{2}^{2}}\right|_{x_{4}=x_{4}^{*}, x_{3}=x_{3}^{\text {min }}, x_{2}=(3-\sqrt{3+t}) / 2}>0$

for all $t<2,56$ and $x_{3}^{\min }>1$ for all $t>1,39$ so that the solution $x_{3}=x_{3}^{\min }$ and $x_{2}^{\min }>x_{2}>0$ cannot be an equilibrium regardless of $t>0$.

(v) When $t>\sqrt{3}, x_{1}^{*}=x_{2}^{*}=0$ and $x_{3}^{*}=x_{4}^{*}=1$ ceases to be an equilibrium (see (i)) and there is no interior solution (see (ii)). In addition, configurations (iii) and (iv) are not equilibrium regardless of trade costs. As a result, we have

$\left.\frac{\mathrm{d} \pi_{\mathrm{A}}}{\mathrm{d} x_{2}}\right|_{x_{1}=x_{1}^{*}}>0$ and $\left.\frac{\mathrm{d} \pi_{\mathrm{B}}}{\mathrm{d} x_{3}}\right|_{x_{4}=x_{4}^{*}} \mathrm{~b} 0$ when $t>\sqrt{3}$,

where we have plugged $x_{1}^{*}=x_{2} / 3$ and $x_{4}^{*}=\left(2+x_{3}\right) / 3$ into (12) and (13). Hence $x_{2}^{*}$ and $x_{3}^{*}$ are determined such that $p_{\mathrm{F} 2}-t=0$ and $p_{\mathrm{H} 3}-$ $t=0$ or, equivalently, $x_{2}^{*}=x_{2}^{\max }\left(x_{3}\right) x_{3}^{*}=x_{3}^{\min }\left(x_{2}\right)$. Under these circumstances, we have $x_{2}^{*}=1 / 2-t / 6$ and $x_{3}^{*}=1 / 2+t / 6$ when $3 \geq t \geq \bar{t}$. In other words, when $t>\sqrt{3}, x_{2}^{*}=1 / 2-t / 6$ and $x_{3}^{*}=1 / 2+$ $t / 6$, each firm exports only one variety even though it produces two varieties.

However, configuration (v) is more complex because the equilibrium is a corner solution under the regime where firms export at least one variety. We have to determine whether this configuration is stable by checking no firm has an incentive to deviate from this equilibrium by exporting at most one variety. Hence, the operating profits for firm $A$ when $t>\bar{t}$ under both regimes can be expressed as follows:

$\Pi_{\mathrm{A}}^{\mathrm{NN}}= \begin{cases}\hat{\Pi}_{\mathrm{A}}^{\mathrm{NN}}=p_{\mathrm{H} 1} q_{\mathrm{H} 1}+\left(p_{\mathrm{F} 1}-t\right) q_{\mathrm{F} 1}+p_{\mathrm{H} 2} q_{\mathrm{H} 2} & \text { if } x_{1}^{*}=\frac{x_{2}}{3} \text { and } x_{2}^{*}=\frac{1}{2}-\frac{t}{6} \\ \tilde{\Pi}_{\mathrm{A}}^{\mathrm{NN}}=p_{\mathrm{H} 1} q_{\mathrm{H} 1}+\left(p_{\mathrm{F} 1}-t\right) q_{\mathrm{F} 1}+p_{\mathrm{H} 2} q_{\mathrm{H} 2} & \text { otherwise }\end{cases}$

where $\tilde{\Pi}_{\mathrm{A}}^{\mathrm{NN}}$ is the profit of firm A when it decides to produce two varieties but exports at most one variety (variety 1 ) when firms adopt the same type of regime (firm B exports only variety 4 ). Note that the same operating profits apply for firm B. Consequently, we get four configurations: where the bottom-left (resp., top-right)

\begin{tabular}{lll}
\hline$x_{2} \leq x_{2}^{\max }$ & $x_{3} \geq x_{3}^{\min }$ & $x_{3} \leq x_{3}^{\min }$ \\
$x_{2} \geq x_{2}^{\max }$ & $\hat{\Pi}_{\mathrm{A}}^{\mathrm{NN}}, \hat{\Pi}_{\mathrm{B}}^{\mathrm{NN}}$ & $\hat{\Pi}_{\mathrm{A}, \tilde{\mathrm{B}}}^{\mathrm{NN}}, \tilde{\Pi}_{\mathrm{B}, \hat{\mathrm{A}}}^{\mathrm{NN}}$ \\
& $\tilde{\Pi}_{\mathrm{A}, \hat{\mathrm{B}}}^{\mathrm{NN}}, \hat{\Pi}_{\mathrm{B}, \tilde{\mathrm{A}}}^{\mathrm{NN}}$ & $\tilde{\Pi}_{\mathrm{A}}^{\mathrm{NN}}, \tilde{\Pi}_{\mathrm{B}}^{\mathrm{NN}}$ \\
\hline
\end{tabular}

case corresponds to the case where firm A (resp., B) produces two varieties but export a single variety while its rival may export its two varieties.

The configuration where $\left\{x_{1}^{*}=x_{2} / 3, \quad x_{2}^{*}=1 / 2-t / 6\right\}$ and $\left\{x_{3}^{*}=1 / 2+t / 6, x_{4}^{*}=\left(2+x_{3}\right) / 3\right\}$ is a (stable) Nash equilibrium if and only if the two following conditions hold: $\hat{\Pi}_{\mathrm{A}}^{\mathrm{NN}}>\tilde{\Pi}_{\mathrm{A}, \hat{\mathrm{B}}}^{\mathrm{NN}}$ and $\hat{\Pi}_{\mathrm{B}}^{\mathrm{NN}}>\tilde{\Pi}_{\mathrm{B}, \hat{\mathrm{A}}}^{\mathrm{NN}}$. As a result, we have to determine the new system of prices under this new regime. Under the bottom-left configuration, the equilibrium prices in country $A$ are given in Appendix A.1 whereas the equilibrium in county $F$ are now given by

$\tilde{p}_{\mathrm{F} 1}=2 t / 3-x_{1}^{2} / 3-2 x_{1} / 3+x_{3}^{2} / 3+2 x_{3} / 3$,

$\tilde{p}_{\mathrm{F} 3}=t / 3+x_{1}^{2} / 3-4 x_{1} / 3-x_{3}^{2} / 3+4 x_{3} / 3$,

$\tilde{p}_{\mathrm{F} 4}=t / 3-x_{4}^{2} / 3+x_{4}+x_{3}^{2} / 6+x_{3} / 3+x_{1}^{2} / 3-4 x_{1} / 3$.

Using this new system of prices, some standard calculations show that the profit of firm $B$ is maximized when $x_{4}^{*}=\left(2+x_{3}\right) / 3$ and $x_{3}^{*}=x_{3}^{\min }=1 / 2+t / 6$. For firm $A, x_{1}^{*}=0$ and $x_{2}^{*}=x_{2}^{\max }=1 / 2-t / 6$ is an equilibrium because

$\left.\frac{\partial \tilde{\Pi}_{\mathrm{A}, \hat{\mathrm{B}}}^{\mathrm{NN}}}{\partial x_{1}}\right|_{x_{1}=0, x_{2}=1 / 2-t / 6}=\frac{(t-3)\left(13 t^{3}-201 t^{2}+2331 t+1377\right)}{2592(3+t)^{2}}<0$

when $x_{3}=1 / 2+t / 6$ and $t<3$ and

$\left.\frac{\partial \tilde{\Pi}_{\mathrm{A}, \hat{\mathrm{B}}}^{\mathrm{NN}}}{\partial x_{2}}\right|_{x_{1}=0, x_{2}=1 / 2-t / 6}=\frac{23}{144} t+\frac{t^{2}}{96}+\frac{3}{32}>0$

when $x_{3}=1 / 2+t / 6$. Hence, we have

$\tilde{\Pi}_{\mathrm{A}, \hat{\mathrm{B}}}^{\mathrm{NN}}=\frac{8829+24138 t-5 t^{4}-90 t^{3}+12024 t^{2}}{15552(3+t)}$

whereas

$\hat{\Pi}_{\mathrm{A}}^{\mathrm{NN}}=-\frac{t^{3}}{729}+\frac{t^{2}}{81}+\frac{17 t}{27}+\frac{1}{27}$

which are positive and increases with $t$ when $3 \geq t \geq \bar{t}$. It appears that $\hat{\Pi}_{\mathrm{A}}^{\mathrm{NN}}>\tilde{\Pi}_{\mathrm{A}, \hat{\mathrm{B}}}^{\mathrm{NN}}\left(\hat{\Pi}_{\mathrm{B}}^{\mathrm{NN}}>\tilde{\Pi}_{\mathrm{B}, \hat{\mathrm{A}}}^{\mathrm{NN}}\right)$ when $t>\bar{t}$ so that $\left\{x_{1}^{*}=x_{2} / 3, x_{2}^{*}=1 / 2-t / 6\right\}$ and $\left\{x_{3}^{*}=1 / 2+t / 6, x_{4}^{*}=\left(2+x_{3}\right) / 3\right\}$ is a Nash equilibrium.

It should be noted that we do not provide the expression of the optimal characteristics of varieties and equilibrium prices corresponding to the configuration $\left(\tilde{\Pi}_{\mathrm{A}}^{\mathrm{NN}}, \tilde{\Pi}_{\mathrm{B}}^{\mathrm{NN}}\right)$. In this case, the analysis is more complex and the gains in terms of results are very limited. Our demonstration is sufficient to show that firms become multi-product when trade costs are high enough and their profits increase with trade costs.

To sum up, the configuration $x_{2}^{*}=0$ and $x_{3}^{*}=1$ is an Nash equilibrium when $t \leq \sqrt{3}$. There exists an interior equilibrium if and only if $\sqrt{3}>t>$ 1.66 with $0<x_{2}^{*}<0.07$ and $x_{3}^{*}=1-x_{2}^{*}$. The first equilibrium is only considered for the analysis since it is Pareto dominant. When $t_{i}^{\max }>t>\sqrt{3}, \quad\left\{x_{1}^{*}=x_{2} / 3, \quad x_{2}^{*}=1 / 2-t / 6\right\} \quad$ and $\quad\left\{x_{3}^{*}=1 / 2+t / 6\right.$, 
$\left.x_{4}^{*}=\left(2+x_{3}\right) / 3\right\}$ is a Nash equilibrium. In this case, the two firms are multiproduct but export only one variety.

\section{Appendix C. The asymmetric case when the multinational supplies the same variety in all countries}

The profit function of firm A is given by Eq. (6) and by Eq. (19) for firm $B$. In this case, price competition is fierce in country $\mathrm{H}$ because trade costs do not matter, and the international firm has an advantage in its domestic country (country F) because of trade costs. Under this configuration, the equilibrium prices are given by

$$
\begin{aligned}
& p_{\mathrm{H} 1}=\frac{x_{3}^{2}}{3}+\frac{2 x_{3}}{3}+\frac{x_{2}^{2}}{6}-\frac{2 x_{2}}{3}-\frac{x_{1}^{2}}{2} \\
& p_{\mathrm{H} 2}=\frac{x_{3}^{2}}{3}+\frac{2 x_{3}}{3}-\frac{x_{2}^{2}}{3}-\frac{2 x_{2}}{3} \\
& p_{\mathrm{H} 3}=-\frac{x_{3}^{2}}{3}+\frac{4 x_{3}}{3}+\frac{x_{2}^{2}}{3}-\frac{4 x_{2}}{3} \\
& p_{\mathrm{H} 4}=-\frac{x_{4}^{2}}{4}+x_{4}+\frac{x_{3}^{2}}{6}+\frac{x_{3}}{3}+\frac{x_{2}^{2}}{3}-\frac{4 x_{2}}{3}
\end{aligned}
$$

and

$$
\begin{aligned}
& p_{\mathrm{F} 1}=\frac{x_{3}^{2}}{3}+\frac{2 x_{3}}{3}-\frac{2 x_{2}}{3}+\frac{x_{2}^{2}}{6}-\frac{x_{1}^{2}}{2}+\frac{2 t}{3}, \\
& p_{\mathrm{F} 2}=\frac{x_{3}^{2}}{3}+\frac{2 x_{3}}{3}-\frac{2 x_{2}}{3}-\frac{x_{2}^{2}}{3}+\frac{2 t}{3}, \\
& p_{\mathrm{F} 3}=-\frac{x_{3}^{2}}{3}+\frac{4 x_{3}}{3}+\frac{x_{2}^{2}}{3}-\frac{4 x_{2}}{3}+\frac{t}{3}, \\
& p_{\mathrm{F} 4}=-\frac{x_{4}^{2}}{2}+x_{4}+\frac{x_{3}^{2}}{6}+\frac{x_{3}}{3}+\frac{x_{2}^{2}}{3}-\frac{4 x_{2}}{3}+\frac{t}{3} .
\end{aligned}
$$

The expression $\mathrm{d} \pi_{\mathrm{A}} / \mathrm{d} x_{1}$ and $\mathrm{dd} \pi_{\mathrm{B}} / \mathrm{d} x_{4}$ are given by (10) and (11), respectively, up to a constant. As above, we have $x_{1}^{*}=x_{2} / 3$ and $x_{4}^{*}=\left(2+x_{3}\right) / 3$ regardless of trade costs. In addition, we have

$\left.\frac{\mathrm{d} \pi_{\mathrm{A}}^{\mathrm{NM}}}{\mathrm{d} x_{2}}\right|_{x_{1}=x_{1}^{*}}=\frac{t^{2}-2\left(x_{3}-x_{2}\right)^{2} t-2 \Lambda_{\mathrm{A}}}{18\left(x_{3}-x_{2}\right)^{2}}<\left.\frac{\mathrm{d} \pi_{\mathrm{A}}^{\mathrm{NN}}}{\mathrm{d} x_{\mathrm{A}}}\right|_{x_{1}=x_{1}^{*}}$.

The incentive to produce a second product for firm A is weaker in comparison with the case in which both firms export. Inter-product competition in country $\mathrm{H}$ is more fierce under the $\mathrm{MN}$ configuration than under the NN configuration. We show that $\mathrm{d} \pi_{\mathrm{A}} / \mathrm{d} x_{2} \leq 0$ regardless of the admissible values of $t, x_{2}$ and $x_{3}$. Using (37), $\mathrm{dd} \pi_{\mathrm{A}}^{\mathrm{NM}} / \mathrm{d} x_{2}$ reaches its maximum value when $t=t_{2}^{\max }$ where $t_{2}^{\max }=\left(x_{3}-x_{2}\right)\left(2+x_{3}+x_{2}\right)$. However, by inspection we can verify that

$\left.\frac{\mathrm{d} \pi_{\mathrm{A}}^{\mathrm{NM}}}{\mathrm{d} x_{2}}\right|_{x_{1}=x_{1}^{*}, t=t_{2}^{\max }}=\frac{13 x_{2}^{2}-2 x_{3} x_{2}-8 x_{2}-4+x_{3}^{2}}{18}<0$

which is negative for all $0 \leq x_{3} \leq 1$ and $0 \leq x_{2} \leq x_{3}$. As a result, for all $t$, $\mathrm{dd} \pi_{\mathrm{A}}^{\mathrm{NM}} / \mathrm{d} x_{2}<0$. Hence, we have $x_{2}^{*}=0$ for all admissible values of $t, x_{2}$ and $x_{3}$.

Therefore, regardless of trade costs, $x_{1}^{*}=x_{2}^{*}=0$. As expected, because of the presence of a foreign firm in country $\mathrm{H}$, firm $\mathrm{A}$ relaxes price competition through product differentiation by producing a single product. In contrast, in country $\mathrm{H}$, the multinational can set higher prices because of trade costs. However, as under the configuration in which both firms export, the choice to produce a second variety for the multinational depends on trade costs. Thus, we have

$\left.\frac{\mathrm{d} \pi_{\mathrm{B}}^{\mathrm{NM}}}{\mathrm{d} x_{3}}\right|_{x_{2}^{*}, x_{4}^{*}}=-\frac{10 x_{3}^{4}-16 x_{3}^{2}+2 t x_{3}^{2}+t^{2}}{18 x_{3}^{2}}$ whereas $\operatorname{sign}\left\{\partial^{2} \pi_{\mathrm{B}}^{\mathrm{NM}} / \partial x_{3}^{2}\right\}=\operatorname{sign}\left\{-9 x_{3}^{4}-x_{3}^{3}+t^{2}\right\}$. In addition, trade occurs if and only if $p_{\mathrm{F} 2}^{*}-t>0$ or, equivalently, $t<x_{3}\left(2+x_{3}\right)$. Some standard calculations reveal that $x_{3}\left(2+x_{3}\right)>t_{2}^{\max }$. ${ }^{17}$

(a) When trade costs reach low values ( $t<t \equiv \sqrt{7}-1<t_{2}^{\max }$ ), it is straightforward to verify (i) $x_{3}^{*}=x_{4}^{*}=1$ is always an equilibrium and (ii) $d d \pi_{B}^{N M} / d x_{3}>0$. Because of low trade costs and fierce price competition, firms are single-product firms, and the maximum differentiation occurs even though asymmetry exists. Hence, when $t<t$, the equilibrium prices are given by $p_{\mathrm{H} 1}^{*}=p_{\mathrm{H} 4}^{*}=1$ and $p_{\mathrm{F} 1}^{*}=p_{\mathrm{F} 2}^{*}=1+2 t / 3$ while $p_{\mathrm{F} 3}^{*}=p_{\mathrm{F} 4}^{*}=1+t / 3$. The market shares are given by $q_{\mathrm{H}}^{\mathrm{A}}=q_{\mathrm{H}}^{\mathrm{B}}=1 / 2$ in country $H$ and by $q_{\mathrm{F}}^{\mathrm{A}}=(1-t / 3) / 2$ and $q_{\mathrm{F}}^{\mathrm{B}}=(1+t / 3) / 2$. As a result, equilibrium profits for firms $A$ and $B$ are

$$
\begin{aligned}
& \pi_{\mathrm{A}}^{\mathrm{NMa}}=\left[1+(1-t / 3)^{2}\right] / 2-\Phi_{N}, \\
& \pi_{\mathrm{B}}^{\mathrm{NMa}}=\left[1+(1+t / 3)^{2}\right] / 2-\Phi_{M} .
\end{aligned}
$$

when $t<t$. The operating profits are higher for the multinational because its domestic market $F$ is protected by trade costs (firm $A$ exports) while no firm has an advantage in country $\mathrm{H}$. As a result, the multinational has the same market share in country $\mathrm{H}$ as its rival firm, while the multinational's market share is higher in its home country (country F).

(b) When trade costs are high enough $\left(t<t<t_{2}^{\max }\left(x_{3}^{*}\right)\right)$, we have $\mathrm{d} \pi_{\mathrm{B}}^{\mathrm{MN}} / \mathrm{d} x_{3}<0$ when $x_{3}=1$. In this case, the multinational (firm B) has an incentive to increase its product range $\left(x_{3}^{*}<x_{4}^{*}<1\right)$. Hence, the optimal characteristics of variety 3 is an interior solution given by $\mathrm{d} \pi_{\mathrm{B}}^{\mathrm{MN}} / \mathrm{d} x_{3}=0$ when $x_{2}^{*}=x_{1}^{*}=0$. More precisely, we obtain:

$$
x_{3}^{*}(t)=8-t+\sqrt{64-16 t-9 t^{2}}
$$

with $x_{3}^{*}(t)=1$ when $t=t$ and $x_{3}^{*}(t)$ decreases with $t$. Hence, when trade costs are high enough, the multinational is a multiproduct firm, even though price competition is fierce in a country. Indeed, high trade costs introduce a distortion of competition in favor of the multinational on its home market (country F). More generally, increasing trade costs raise the multinational's market power in country $F$. In this case, the revenue effect caused by the introduction of a new variety is high enough to offset the cannibalization effect.

The expressions of equilibrium profits are as follows ${ }^{18}$ :

$$
\begin{aligned}
\pi_{\mathrm{A}}^{\mathrm{NMb}} & =\Pi_{\mathrm{A}}^{\mathrm{NMb}}-\Phi_{N} \\
\pi_{\mathrm{B}}^{\mathrm{NMb}} & =\Pi_{\mathrm{B}}^{\mathrm{NMb}}-\Phi_{M}
\end{aligned}
$$

where

$$
\begin{gathered}
\Pi_{\mathrm{A}}^{\mathrm{NMb}} \equiv \frac{8 x_{3}^{* 2}+8 x_{3}^{* 3}+2 x_{3}^{* 4}-2 x_{3}^{* 2} t-4 x_{3}^{*} t+t^{2}}{18 x_{3}^{*}}, \\
\Pi_{\mathrm{B}}^{\mathrm{NMb}} \equiv \frac{-10 x_{3}^{* 4}-6 x_{3}^{* 2} t+48 x_{3}^{* 2}+24 x_{3}^{*} t+16 x_{3}^{*}+3 t^{2}}{54 x_{3}^{*}} .
\end{gathered}
$$

To summarize, if one firm exports to serve the foreign country while the other firm is a multinational corporation supplying the same varieties in each country, then (i) both firms are single-product firms when trade costs are low enough $(t<t)$; (ii) the multinational

\footnotetext{
17 Note that $x_{3}\left(2+x_{3}\right)>t_{\max }^{\mathrm{NN}}$ is equivalent to $x_{3}\left(2+x_{3}\right)>3\left(2 x_{3}-1\right)$ or to $x_{3}^{2}-4 x_{3}+3>0$ which is verified as long as $1>x_{3}>0$.

18 Note that there is no discontinuity when the regime moves from case (a) to case (b). Indeed, when $t=t, x_{\mathrm{B}}^{\mathrm{F}}(t)=1$ and, thus, $(25)=(39)$ as well as $(26)=(40)$.
} 
becomes a multi-product firm while its rival remains a single-product firm when trade costs become sufficiently high $(t>t)$.

\section{Appendix D. Technical characteristics under the asymmetric case}

Using equilibrium prices given in Appendix A.3, we have

$$
\begin{aligned}
\frac{\mathrm{d} \pi_{\mathrm{A}}^{\mathrm{NM}}}{\mathrm{d} x_{1}} & =-\frac{\left(x_{1}+x_{2}\right)\left(3 x_{1}-x_{2}\right)}{4} \text { and } \frac{\mathrm{d} \pi_{\mathrm{B}}^{\mathrm{NM}}}{\mathrm{d} x_{\mathrm{B}}^{\mathrm{H}}} \\
& =\frac{\left(4-x_{\mathrm{B}}^{\mathrm{H}}-x_{2}\right)\left(4+x_{2}-3 x_{\mathrm{B}}^{\mathrm{H}}\right)}{18}>0
\end{aligned}
$$

so that $x_{1}^{*}=x_{2} / 3$ and $x_{\mathrm{B}}^{\mathrm{H}^{*}}=1$ regardless of trade costs and the technical characteristics fixed by the rival. It appears that exports take place if $p_{\mathrm{F} 2}-t>0$ or, equivalently,

$\frac{2\left(x_{B}^{F}-x_{2}\right)+\left[\left(x_{B}^{F}\right)^{2}-x_{2}\right]-t}{3}>0$.

In addition, we get

$\left.\frac{\mathrm{d} \pi_{\mathrm{B}}^{\mathrm{NM}}}{\mathrm{d} x_{\mathrm{B}}^{\mathrm{F}}}\right|_{x_{\mathrm{B}}^{\mathrm{H}}=1}=\frac{-\left[4 x_{\mathrm{B}}^{\mathrm{F}}-4 x_{2}+x_{2}^{2}+t-\left(x_{\mathrm{B}}^{\mathrm{F}}\right)^{2}\right]\left[-4 x_{\mathrm{B}}^{\mathrm{F}}+4 x_{2}+3\left(x_{\mathrm{B}}^{\mathrm{F}}\right)^{2}-4 x_{\mathrm{B}}^{\mathrm{F}} x_{2}+x_{2}^{2}+t\right]}{18\left(x_{\mathrm{B}}^{\mathrm{F}}-x_{2}\right)^{2}}$

when $x_{1}=x_{2} / 3$ and

$\left.\frac{\mathrm{d} \pi_{\mathrm{A}}^{\mathrm{NM}}}{\mathrm{d} x_{2}}\right|_{x_{1}=x_{2} / 3}=\frac{t^{2}}{18\left(x_{\mathrm{B}}^{\mathrm{F}}-x_{2}\right)^{2}}-\frac{2 t}{18}+\frac{10 x_{2}^{2}-18 x_{2}-2 x_{\mathrm{B}}^{\mathrm{F}} x_{2}+\left(x_{\mathrm{B}}^{\mathrm{F}}\right)^{2}}{18}-\frac{7}{18}$

when $x_{\mathrm{B}}^{\mathrm{H}}=1$.

Note that

$\left.\frac{\mathrm{d} \pi_{\mathrm{A}}^{\mathrm{NM}}}{\mathrm{d} x_{2}}\right|_{x_{1}=x_{2} / 3, x_{2}=0}=\frac{t^{2}-2 t-6}{18}$,

when $x_{B}^{H}=x_{B}^{F}=1$ and

$\left.\frac{\mathrm{d} \pi_{\mathrm{B}}^{\mathrm{NM}}}{\mathrm{d} x_{\mathrm{B}}^{\mathrm{F}}}\right|_{x_{\mathrm{B}}^{\mathrm{H}}=x_{\mathrm{B}}^{\mathrm{F}}=1}=\frac{(3+t)(1-t)}{18}$

when $x_{2}=0$, implying that $x_{1}=x_{2}=0$ and $x_{\mathrm{B}}^{\mathrm{H}}=x_{\mathrm{B}}^{\mathrm{F}}=1$ is an equilibrium as long as $t \leq 1$.

Then, $\left.\frac{\mathrm{d} \pi_{\mathrm{B}}^{\mathrm{NM}}}{\mathrm{d} x_{\mathrm{B}}^{\mathrm{F}}}\right|_{x_{1}=x_{2} / 3, x_{\mathrm{B}}^{\mathrm{H}}=1}=0$ if $x_{\mathrm{B}}^{\mathrm{F}}=2 / 3+2 x_{2} / 3+\sqrt{4-4 x_{2}+x_{2}^{2}-3 t} / 3$.

In this case, $x_{\mathrm{B}}^{\mathrm{F}}<1$ if and only if $x_{2}<\sqrt{1-t}$.

Further, when $4 / 3>t>1, x_{2}=0$ and $x_{\mathrm{B}}^{\mathrm{F}}=2 / 3+\sqrt{4-3 t} / 3$ is a stable configuration because

$\left.\frac{\mathrm{d}^{2} \pi_{\mathrm{B}}^{\mathrm{NM}}}{\mathrm{d} x_{\mathrm{B}}^{\mathrm{F} 2}}\right|_{x_{1}=x_{2} / 3, x_{\mathrm{B}}^{\mathrm{H}}=1}<0$ and $\left.\frac{\mathrm{d} \pi_{\mathrm{A}}^{\mathrm{NM}}}{\mathrm{d} x_{2}}\right|_{x_{1}=x_{2} / 3, x_{\mathrm{B}}^{\mathrm{H}}=1} \mathrm{~b} 0$

when $x_{2}=0$ and $x_{B}^{F}=2 / 3+\sqrt{4-3 t} / 3$ for all $t$ from 1 to $4 / 3$. Hence, $x_{2}=0$ and $x_{B}^{F}=2 / 3+\sqrt{4-3 t} / 3$ is an equilibrium when $4 / 3 \geq t>1$.

\section{References}

Anderson, S., de Palma, A., Thisse, J.-F., 1992. Discrete Choice Theory of Product Differentiation. MIT Press, Cambridge, MA.

Baldwin, R., Gu, W., 2009. The Impact of Trade on Plant Scale, Production-Run Length and Diversication. In: Dunne, T., Jensen, J., Roberts, M.J. (Eds.), Producer Dynamics: New Evidence from Micro Data. Chicago University Press, Chicago.

Baldwin, R., Ottaviano, G., 2001. Multiproduct multinationals and reciprocal FDI dumping. Journal of International Economics 54 (2), 429-448.

Behrens, K., Picard, P., 2008. Bidding for horizontal multinationals. Journal of the European Economic Association 6, 1244-1278.

Ben-Akiva, M., De Palma, A., Thisse, J.-F., 1989. Spatial competition with differentiated products. Regional Science and Urban Economics 19, 5-19.

Bernard, A., Jensen, J., Redding, S., Schott, P., 2009. Firms in international trade. Journal of Economic Perspective 21, 105-130.

Bernard, A., Redding, S., Schott, P., 2011. Multi-product firms and trade liberalization. Quarterly Journal of Economics 126 (3), 1271-1318.

Berthou, A., Fontagné, L., forthcoming. How do multi-product exporters react to a change in trade costs? forthcoming in Scandinavian Journal of Economics.

Blanchard, P., Gaigné, C., Mathieu, C., 2007. Foreign Direct Investment: Lessons from Panel Data. In: Mathyas, L., Sevestre, P. (Eds.), The Econometrics of Panel Data. Springer.

Blanchard, P., Gaigné, C., Mathieu, C., 2010. The International Strategies of Firms: The role of Endogenous Product Differentiation. Micro-Dyn Working Paper No. 06/10.

Brainard, S.L., 1997. An empirical assessment of the proximity-concentration trade-off between multinational sales and trade. American Economic Review 87 (3), 520-544.

Brander, J., Eaton, J., 1984. Product line rivalry. American Economic Review 74 (3), 323-333.

Brander, J., Krugman, P., 1983. A 'reciprocal dumping' model of international trade. Journal of International Economics 15 (3-4), 313-323.

D'Aspremont, C., Gabszewicz, J., Thisse, J.-F., 1979. On Hotelling's stability in competition. Econometrica 47, 1145-1150.

DeFraja, G., Norman, G., 2004. Product differentiation and the location of international production. Journal of Economics and Management Strategy 13 (1), 151-170.

Eckel, C., Neary, P., 2010. Multi-product firms and flexible manufacturing in the global economy. Review of Economic Studies 77 (1), 188-217.

Ekholm, K., 1997. Factor endowments and the pattern of affiliate production by multinational enterprises. Credit Research Paper 97/19.

Feenstra, R., Ma, H., 2008. Optimal Choice of Product Scope for Multiproduct Firms under Monopolistic Competition. In: Helpman, E., Marin, D., Verdier, T. (Eds.), The Organization of Firms in a Global Economy. Harvard University Press, Cambridge M.A.

Greenaway, D., Lloyd, P., Milner, C., 1998. Intra-Industry FDI and Trade Flows: New Measures of Globalisation of Production. GLM Research Paper 85/5. University of Nottingham.

Horstman, I., Markusen, J., 1992. Endogenous market structures in international trade. Journal of International Economics 32 (1-2), 109-129.

Hotelling, H., 1929. Stability in competition. Economic Journal 39 (1), 41-57.

Iacovone, L., Javorcik, B., 2010. Multi-product exporters: product churning, uncertainty and export discoveries. Economic Journal 120 (544), 481-499.

Klemperer, P., 1992. Equilibrium product lines: competing head-to-head may be less competitive. American Economic Review 82 (4), 741-755.

Lyons, B., 1984. The Pattern of International Trade in Differentiated Products: An Incentive for the Existence of Multinational Firms. In: Kierzkowski (Ed.), Monopolistic Competition and International Trade. Clarendon Press, Oxford.

Manez, J., Waterson, M., 1998. Multiproduct Firms and Product Differentiation: A Survey. Warwick Economic Research Paper, No 594.

Markusen, J., 2002. Multinational Firms and the Theory of International Trade. MIT Press, Cambridge.

Martinez-Giralt, X., Neven, D., 1988. Can price competition dominate market segmentation? Journal of Industrial Economics 36, 431-442.

Mathieu, C., 1997. International enterprises and endogeneous market structure Annales d'Economie et de Statistiques 47, 171-195.

Mayer, T., Melitz, M., Ottaviano, G., 2011. Market Size, Competition and the Product Mix of Exporters. NBER Working Paper No. 16959.

Motta, M., 1994. International trade and investments in a vertically differentiated industry. International Journal of Industrial Organization 12 (2), 179-196.

Navaretti, G., Venables, A., 2004. Multinational Firms in the World Economy. Princeton University Press.

Neary, P., 2009. Trade costs and foreign direct investments. International Review of Economics and Finance 18 (2), 207-218.

Norman, G., Thisse, J.-F., 1996. Product variety and welfare under discriminatory and mill pricing policies. Economic Journal 106, 76-91.

Ojah, K., Monplaisir, L., 2003. Investors' valuation of global product design and development. Journal of International Business Studies 34 (4), 457-472.

Rugman, A.M., 1987. Multinationals and trade in services: a transaction cost approach. Weltwirtschaftliches Archiv 123 (4), 651-667.

Shaked, A., Sutton, J., 1990. Multiproduct firms and market structure. Rand Journal of Economics 21, 45-62. 